\title{
The Earthquake-Source Inversion Validation (SIV) Project
}

\begin{abstract}
by P. Martin Mai, Danijel Schorlemmer, Morgan Page, Jean-Paul Ampuero, Kimiyuki Asano, Mathieu Causse, Susana Custodio, Wenyuan Fan, Gaetano Festa, Martin Galis, Frantisek Gallovic, Walter Imperatori, Martin Käser, Dmytro Malytskyy, Ryo Okuwaki, Fred Pollitz, Luca Passone, Hoby N. T. Razafindrakoto, Haruko Sekiguchi, Seok Goo Song, Surendra N. Somala, Kiran K. S. Thingbaijam, Cedric Twardzik, Martin van Driel, Jagdish C. Vyas, Rongjiang Wang, Yuji Yagi, and Olaf Zielke
\end{abstract}

\begin{abstract}
Finite-fault earthquake source inversions infer the (time-dependent) displacement on the rupture surface from geophysical data. The resulting earthquake source models document the complexity of the rupture process. However, multiple source models for the same earthquake, obtained by different research teams, often exhibit remarkable dissimilarities. To address the uncertainties in earthquake-source inversion methods and to understand strengths and weaknesses of the various approaches used, the Source Inversion Validation (SIV) project conducts a set of forward-modeling exercises and inversion benchmarks. In this article, we describe the SIV strategy, the initial benchmarks, and current SIV results. Furthermore, we apply statistical tools for quantitative waveform comparison and for investigating source-model (dis)similarities that enable us to rank the solutions, and to identify particularly promising source inversion approaches. All SIV exercises (with related data and descriptions) and statistical comparison tools are available via an online collaboration platform, and we encourage source modelers to use the SIV benchmarks for developing and testing new methods. We envision that the SIV efforts will lead to new developments for tackling the earthquake-source imaging problem.
\end{abstract}

Online Material: Figures of velocity-density structure, sourcereceiver geometries, slip-rate functions, input and inverted rupture models, quantitative waveform comparisons. Tables of scalar source parameters and dissimilarity values.

\section{INTRODUCTION}

Finite-fault earthquake-source inversions infer the spatiotemporal rupture evolution on one or more fault planes using geologic information, seismic and/or geodetic data, and potentially including also (or using exclusively) tsunami measurements. Source inversions provide important information on the complexity of the earthquake rupture process. Earthquake source-scaling studies use finite-fault information to determine rupture parameters for developing empirical scaling laws that shed light on earthquake mechanics (Somerville et al., 1999; Mai and Beroza, 2000; Mai et al., 2005; Manighetti et al., 2005; Blaser et al., 2010; Strasser et al., 2010). Researchers use the space-time-dependent source inversion results to develop spontaneous dynamic rupture models and to work toward a general understanding of earthquake rupture physics (e.g., Heaton, 1990; Bouchon, 1997; Ide and Takeo, 1997; Day et al., 1998; Page et al., 2005; Tinti et al., 2005; Mai et al., 2006; Gabriel et al., 2012; Causse et al., 2013). For individual earthquakes, source studies reveal cascading failure of complex fault systems (Yue et al., 2012) or rerupturing of the hypocentral region (Lee et al., 2011). Thus, finite-fault inversions provide the key for discerning earthquake source complexity.

A quantitative understanding of rupture complexity is also essential for ground-motion prediction studies that require an adequate characterization of slip heterogeneity to generate realistic scenario earthquakes (e.g., Mai, 2009). Slip-heterogeneity characterizations are based on source models of past earthquakes (e.g., Mai and Beroza, 2002; Lavallée et al., 2006; Causse et al., 2010; Gusev, 2011; K. K. S. Thingbaijam and P. M. Mai, unpublished manuscript, 2016). Inference on rupture speed and its variation (e.g., Archuleta, 1984; Dunham and Archuleta, 2004; Bouchon et al., 2010) provide evidence for the occurrence of supershear rupture velocity, which is critical not only for realistic ground-motion simulations, but also for understanding the dynamic rupture process. Finite-fault slip maps are also needed to compute postmainshock stress 
changes that can be related to the aftershock activity (King et al., 1994; Stein et al., 1997).

Much of our understanding of earthquake source complexity stems from finite-source rupture models, building on the pioneering work of Olson and Apsel (1982). A detailed review of source inversion techniques is beyond the scope of this article; instead we refer to Ide (2007). To illustrate the general concept, we use the representation theorem (Aki and Richards, 2002) written as

$$
u_{n}(\mathbf{x}, t)=\int d \tau \iint_{\Sigma}\left[s_{i}(\xi, \tau)\right] \times c_{i j p q} \times v_{j} \times G_{n p, q}(\mathbf{x}, t-\tau ; \xi, 0) d \Sigma,
$$

in which $\left[s_{i}(\xi, \tau)\right]$ represents the slip velocity at locations $\xi$ and times $\tau, c_{i j p q}$ is the elasticity tensor, $v_{j}$ is the vector normal to the fault surface $\Sigma$, and $G_{n p, q}$ denotes the medium response to the generalized force couple in the $x_{q}$ direction with force in the $p$ direction. $u_{n}(\mathbf{x}, t)$ is the $n$th component of the ground-motion time series at location $\mathbf{x}$. The representation theorem in equation (1) describes a linear relation between the rupture process $s_{i}(\xi, \tau)$ on the fault and the observed displacement $u_{n}(\mathbf{x}, t)$. For practical purposes, Earth structure, fault-receiver geometry, and the force-couples responses are combined into the Green's function $G(x, \xi, t)$. When solving the inverse problem, we seek a kinematic parameterization of the space-time-dependent rupture process (e.g., discrete basis functions for the slip-rate distribution $\left.s_{i}(\xi, \tau)\right)$ that minimizes the differences between recorded ground motions and the predictions (computed using equation 1 ). In principle, equation (1) results in a linear inverse problem, but one that is inherently underdetermined. To solve it, one must reduce the dimension of the model space to make the problem overdetermined, for instance through regularization of the solution by applying a spatial and/or temporal operator (or both).

For computational purposes, the rupture surface in equation (1) is discretized into small elements (called subfaults) in which the kinematic rupture process is parameterized using one or more elementary slip-rate functions. Each of these subfaults is activated as the rupture front sweeps over the fault plane with rupture speed $v_{r}$. In slip inversions, $v_{r}$ is often assumed constant, in which case the inversion is run several times at different values of $v_{r}$ to find the optimal $v_{r}$ that leads to the minimum misfit. A linear multi-time-window source inversion applies more than one elementary slip-rate function to represent the rupture evolution on a single subfault. Rupture speed $v_{r}$ may be spatially variable, which can be achieved by solving for the rupture-onset time at each subfault. Typically, this is done using a nonlinear inversion approach. When using the discretized form of equation (1) for earthquake-source inversion, the inferred rupture model depends also on the chosen discretization, parameterization, and misfit function, as well as on the particular method for solving the inverse problem.

Many source inversion methods have been proposed, either as constrained linear inversions (e.g., Olson and Apsel, 1982; Hartzell and Heaton, 1983) or nonlinear inversions that search the model space without stringent constraints (e.g., Hartzell et al., 1996; Liu and Archuleta, 2004; Monelli and
Mai, 2008). These inversions use seismic data (strong-motion, teleseismic; e.g., Wald et al., 1991; Yoshida et al., 1996), geodetic measurements (to constrain fault geometry and the final static displacement; e.g., Jónsson et al., 2002), or a combination of both, potentially augmented with information on surface rupture or other constraints (e.g., Asano et al., 2005). Slip during large tsunamigenic megathrust earthquakes can be constrained by tsunami waveform data (e.g., Satake et al., 2013). Recently, Gallovic et al. (2015) developed a regularized linear inversion that is unconstrained in the temporal rupture evolution. The required Green's functions $G(x, \xi, t)$ are computed using a variety of techniques and parameterizations of the Earth's crust (layered 1D models, full 3D models; e.g., Graves and Wald, 2001; Wald and Graves, 2001), whereas some methods use small earthquakes as empirical Green's functions (Dreger, 1994).

Earthquake-source inversions provide tools and models to investigate earthquake rupture processes and have become an almost routine analysis for studying rupture kinematics. For large and important earthquakes, near-real-time finite-fault source inversions are available online only a few hours after the event (e.g., Hayes, 2011). Results of many finite-fault studies are collected in the online SRCMOD database (Mai and Thingbaijam, 2014; see also Data and Resources). However, the resolution and robustness of these finite-fault rupture models is not well understood. For instance, significant differences are seen for rupture models of the same earthquake but inferred by different researchers. Figure 1 shows four slip models for the $1999 M_{\mathrm{w}} 7.6$ İzmit earthquake (out of six solutions in the SRCMOD database) that are strikingly different. The discrepancies in these slip distributions have been described previously (Beresnev, 2003; Ide et al., 2005) and may be attributed to (1) differences in the data selection and processing; (2) the methods used for computing the Green's functions for each dataset; (3) the assumed Earth structure, fault geometry, and other geophysical parameters; and (4) the method and parameterization for the inversion itself (linearized or fully nonlinear inversion; spatial and temporal discretization; applied smoothing and regularization). Items (2-3) are directly related to using equation (1).

Because of our imperfect knowledge of Earth's structure and fault geometry, and because of insufficient data, the source inversion problem is nonunique: many rupture-model solutions may fit the data equally well. Also, rigorous uncertainty quantification in earthquake source studies is needed but, unfortunately, is often neglected. An ensemble of solutions is obtained when varying inversion input parameters and processing steps to investigate the corresponding model sensitivities (e.g., Custódio et al., 2005; Konca et al., 2013; Liu et al., 2006; Hartzell et al., 2007). Bayesian approaches provide a more formal way to quantify rupturemodel uncertainties (Monelli et al., 2009; Duputel et al., 2012; Minson et al., 2013), but estimating the full posterior probability density functions of the inverted source quantities is computationally still demanding (e.g., Bernauer et al., 2014; Dettmer et al., 2014; Razafindrakoto and Mai, 2014).

To better understand the limits and robustness of earthquake-source inversion methods, and to examine how the 
(a)

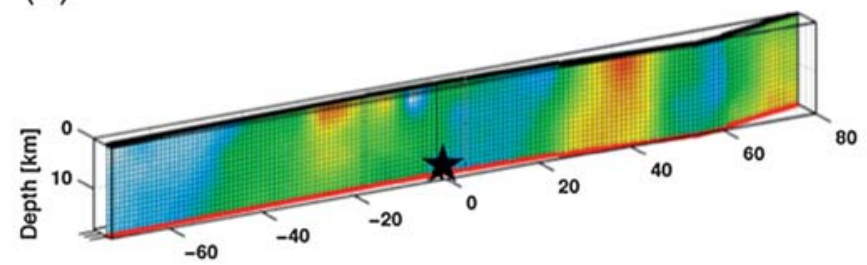

(c)

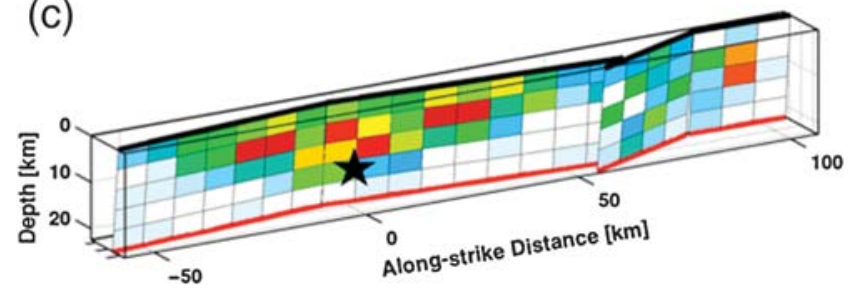

(b)

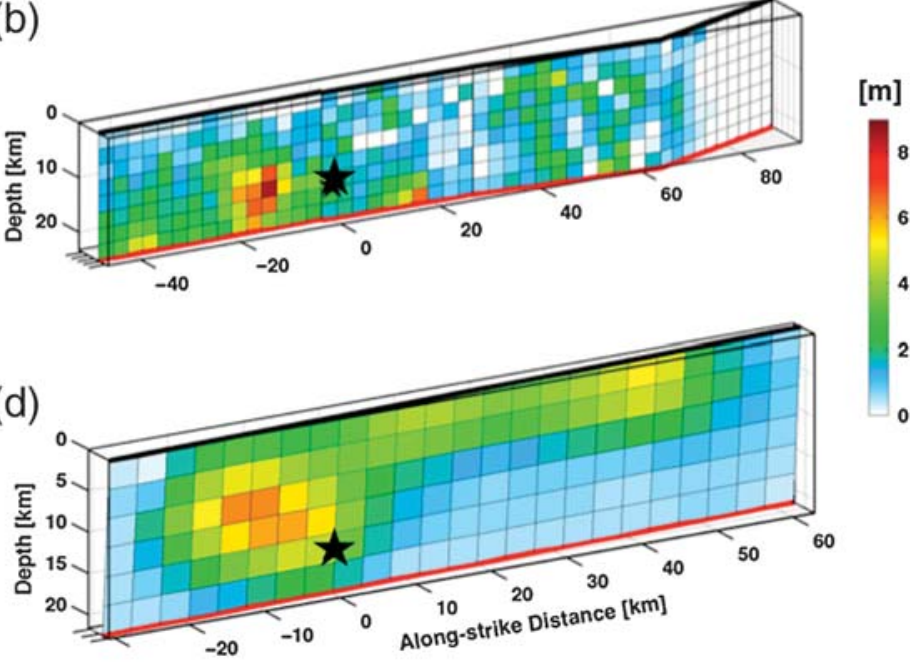

A Figure 1. Selected finite-source rupture models for the $1999 M_{\mathrm{w}} 7.6$ İzmit earthquake (Turkey), obtained using different inversion strategies and different datasets. Black stars mark the hypocenter. Colors indicate fault slip (in meters). Note the pronounced dissimilarities of the slip distributions for this event. The inversion results are from (a) Bouchon et al. (2002), (b) Sekiguchi and Iwata (2002), (c) Delouis et al. (2002), and (d) Yagi and Kikuchi (2000).

different steps of the source inversion workflow (steps 1-4, above) affect the rupture-model results, the earthquake Source Inversion Validation (SIV) initiative was launched (Page et al., 2011). The SIV project extends a previous source inversion testing study (Mai et al., 2007) and seeks to develop new methods for uncertainty quantification in earthquake source inversions. A long-term goal of the SIV initiative is also to develop a (semi) automated source inversion platform on which various approaches can be tested simultaneously with minimal user intervention to arrive at transparent, fully testable, and reproducible earthquake source models with comprehensively quantified uncertainties.

Below, we introduce the SIV initiative, describe the strategy of our work, and report the results achieved so far, which include newly developed inversion methods and statistical analysis tools that are a direct outcome of the SIV collaboration.

\section{STRATEGY}

The workflow for finite-fault earthquake source inversions requires several steps, including data selection and data processing, choosing and running a proper forward-solver with adequate input parameterization, and conducting the actual inversion. Each of these steps influences the resulting rupture model. The SIV initiative tries to address all aspects of this workflow and to isolate their effects on the inversion results. Correspondingly, our strategy is to begin with simple forwardmodeling exercises to test various Green's function computation codes and their use. Next, we define a suite of inversion benchmarks with increasing complexity. Either certain metadata are not specified, or only with uncertainty, or noise is added to the synthetics. Including geometrical variations in the rupture model for forward simulations adds another layer of intricacy to the benchmarks. The Southern California Earthquake Center (SCEC)/U.S. Geological Survey (USGS) code verification exercise (Harris et al., 2009) follows a similar strategy through a set of forward-modeling problems with increasing complexity for testing numerical methods for dynamic earthquake rupture simulations.

To set up the inversion benchmarks, a subgroup of the SIV team generates input (target) earthquake-rupture models with varying degrees of source complexity for which forward simulations are run to compute synthetic datasets. Depending on the benchmark, these may comprise only near-field seismic waveforms or also include Global Positioning System (GPS) displacements and teleseismic synthetics. The synthetic datasets are disseminated via an online collaboration platform (see Data and Resources). The input source model used for each benchmark is not publicized until the exercise is officially concluded. Registered participants use the collaboration platform to submit their rupture-model solutions and predicted datasets in specific data formats. The platform provides quantitative analysis tools to compare inversion solutions and predicted data between different participants or with respect to the known input model (released after the particular benchmark is concluded). All benchmark exercises and related data remain accessible such that interested scientists can use these for follow-up research even after the official closure date.

In the long term, we envision an automated testing center, inspired by the Collaboratory for the Study of Earthquake Predictability (e.g., Zechar $e t$ al., 2010). The goal is to establish a computational platform on which numerous source inversion codes are applied to a large number of benchmark exercises in a transparent manner. In such a testing center, user-driven decisions are replaced by algorithmically derived parameter selections to generate testable and reproducible source inversions 


\begin{tabular}{|c|c|c|c|c|c|c|}
\hline \multicolumn{7}{|c|}{$\begin{array}{l}\text { Table } 1 \\
\text { List of Source Inversion Validation (SIV) Benchmark Exercises (Status October 2015) }\end{array}$} \\
\hline $\begin{array}{l}\text { Benchmark } \\
\text { (SIV label) }\end{array}$ & $\begin{array}{l}\text { Type of } \\
\text { Problem }\end{array}$ & Source & $\begin{array}{c}\text { Faulting } \\
\text { Style } \\
\end{array}$ & Earth Structure & Data & $M_{\mathrm{w}}$ \\
\hline sspo & Forward & $\begin{array}{c}\text { Point } \\
\text { source }\end{array}$ & Strike-slip & 1D layered & Near source & 5.0 \\
\hline$d s p 0$ & Forward & $\begin{array}{l}\text { Point } \\
\text { source }\end{array}$ & Reverse & 1D layered & Near source & 5.0 \\
\hline ssefo & Forward & Finite fault & Strike slip & 1D layered & Near source & 6.11 \\
\hline dsefo & Forward & Finite fault & Reverse & 1D layered & Near source & 6.14 \\
\hline inv1 & Inversion & Finite fault & Strike slip & 1D layered & Near source & 6.6 \\
\hline inv2a & Inversion & Finite fault & Normal & 1D layered & Near source & 7.0 \\
\hline$i n v 2 b$ & Inversion & Finite fault & Normal & $1 \mathrm{D}$ layered $+3 \mathrm{D}$ randomness & Near source + GPS* & 7.0 \\
\hline inv3 & Inversion & Finite fault & Strike slip & $\begin{array}{l}\text { 3D for near source; } 1 \mathrm{D} \text { radial } \\
\text { for teleseismic with station- } \\
\text { dependent } \\
\text { local 1D structure }\end{array}$ & $\begin{array}{l}\text { Near source }+ \\
\text { teleseismic }\end{array}$ & 7.8 \\
\hline
\end{tabular}

with proper uncertainty quantification (e.g., Mesirov, 2010; Eddy et al., 2012; Lees, 2012).

Next, we describe the forward-modeling exercises and inversion benchmarks of the SIV project (summarized in Table 1). We then introduce the statistical comparison tools that the SIV platform provides and discuss their use to assess the solution quality and to develop a ranking scheme. Based on the results obtained so far, we provide a summary and set of recommendations for earthquake-source inversion studies and the continuation of the SIV project.

\section{FORWARD-MODELING EXERCISES}

To test numerical methods for Green's function calculations in source inversion studies, we conduct two sets of forward-modeling exercises for the near-fault region. We first examine point-source synthetics for near-field seismic waves, and then we test the methods with respect to precisely specified finitefault rupture models.

\section{Near-Source Green's Function Computation}

We consider two point-source cases: a purely left-lateral strikeslip event on a vertical fault and a reverse-faulting event on a $40^{\circ}$ dipping fault. The rupture is parameterized as a $1 \mathrm{~km} \times 1 \mathrm{~km}$ uniform-slip area over which a boxcar slip-rate function of duration $\tau_{r}=0.2 \mathrm{~s}$ acts. The shear modulus at the source depth of $Z=10 \mathrm{~km}$ yields a moment magnitude $M_{\mathrm{w}} \quad 5.0$ $\left(M_{0}=3.5 \times 10^{16} \mathrm{~N} \cdot \mathrm{m}\right)$. Synthetic seismograms are computed in the $0-5 \mathrm{~Hz}$ frequency range. (E) Figure $S 1$ (available in the electronic supplement to this article) displays the 1D planelayered velocity-density structure and the source-receiver configuration.

Figure 2 depicts three-component synthetic seismograms at selected locations, computed by eight different research teams using four different codes. AX refers to the Axitra code
(Bouchon, 1981; Coutant, 1989), CS stands for the COMPSYN package (Olson et al., 1984; Spudich and Xu, 2002), and ZR denotes the Zhu and Rivera (2002) method. These methods compute complete near-source seismic waves using a wavenumber-integration approach. DG represents a high-order discontinous Galerkin method for seismic-wavefield simulations (Käser and Dumbser, 2006; Käser et al., 2007). To facilitate misfit quantification, we arbitrarily choose AX1 as the reference case.

The waveform comparison reveals that noticeable differences occur even for the point-source Green's function test. Visual inspection of Figure 2 suggests good agreement between most waveforms (aside from the CS3 case, in which the computations were carried out with improper input parameter choices). However, we observe amplitude variations (quantified by the scale factor $[\mathrm{SF}]$ used for amplitude normalization), most likely due to incorrect seismic-moment specification or code-internal rescaling factors. Cross-correlation values (XC, given as the maximum cross-correlation value, not accounting for phase differences) are typically above $\sim 0.95$ for both rupture styles, although lower values occur for some reverse-faulting calculations (Fig. 2b). In addition, small arrival-time differences of the $P$ wave and also later phases are recognizable. In the reverse-faulting case, the $Y$-component seismograms (Fig. 2b, center) exhibit large differences in secondary phases arriving after the dominant $S$-wave pulse. These phase differences lead to variations in the corresponding L2 norms, computed after normalizing each waveform with its corresponding SF with respect to the reference waveforms AX1.

This near-field Green's function validation shows that the tested methods overall provide consistent results under the premise that the codes are used correctly (i.e., the required input parameters are properly specified for the given problem). However, variations in amplitude and phase-arrival times are present. We attribute the amplitude variations to incorrect 
(a)
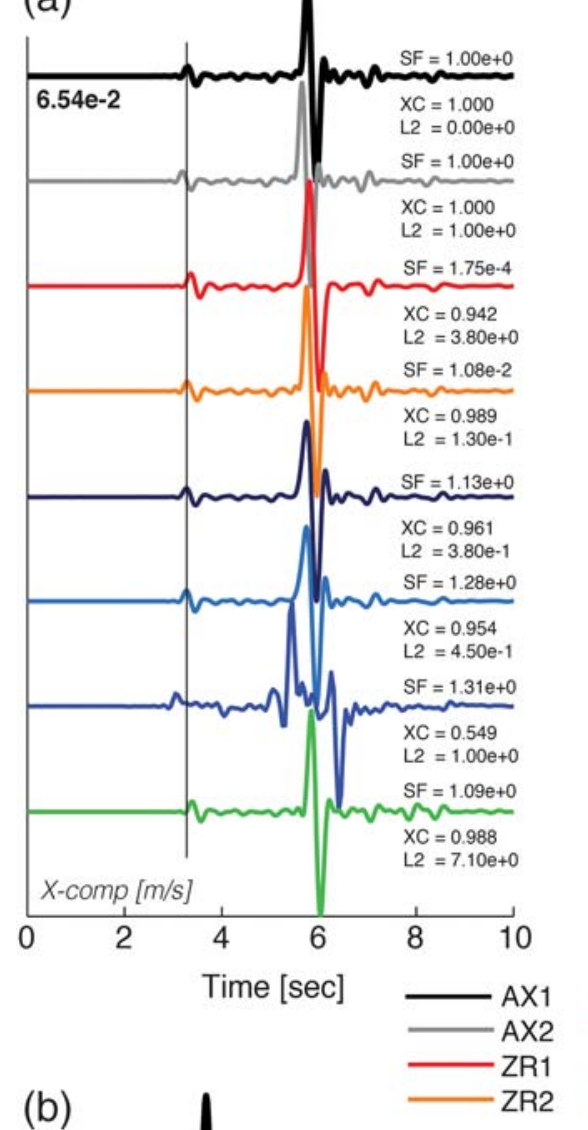

(b)

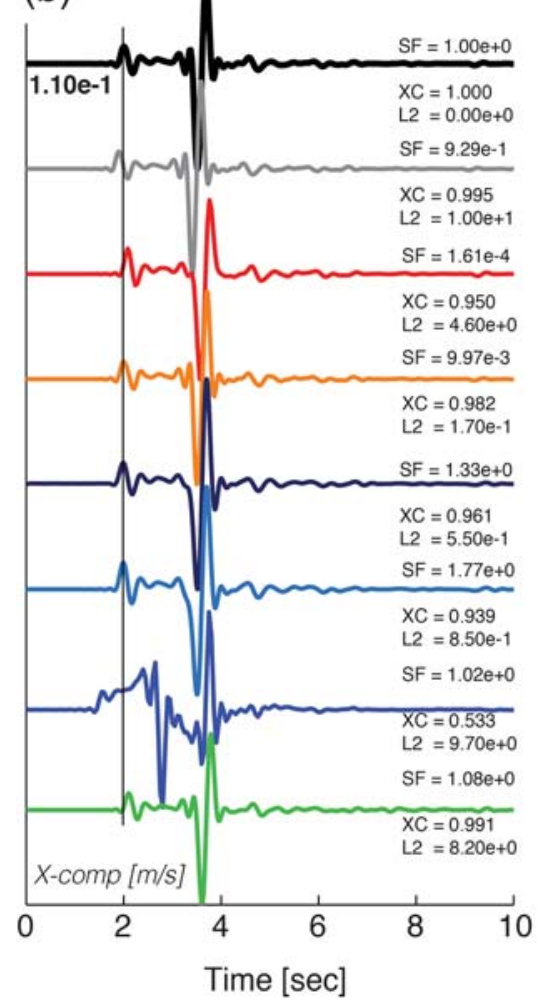

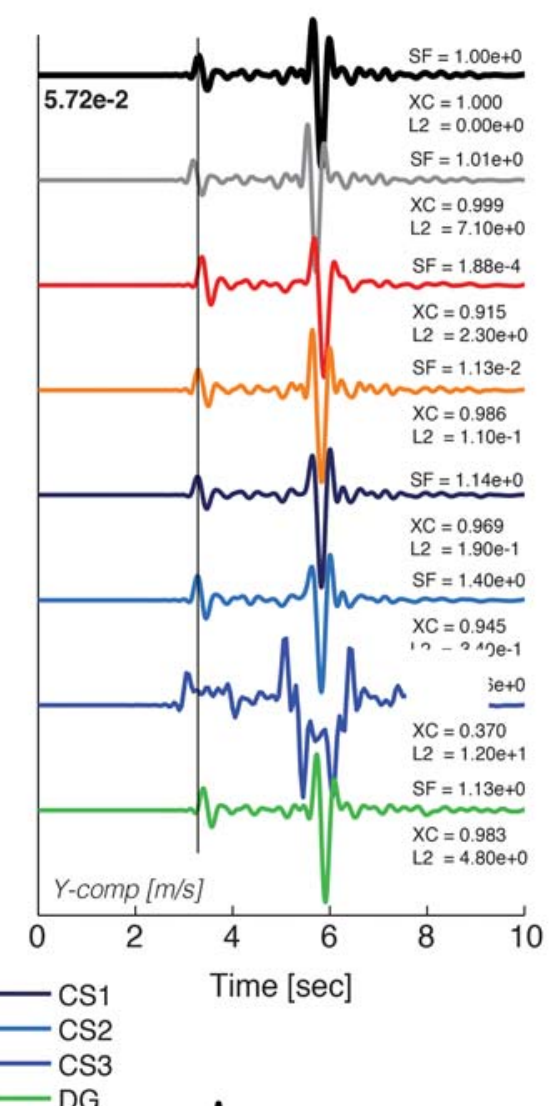

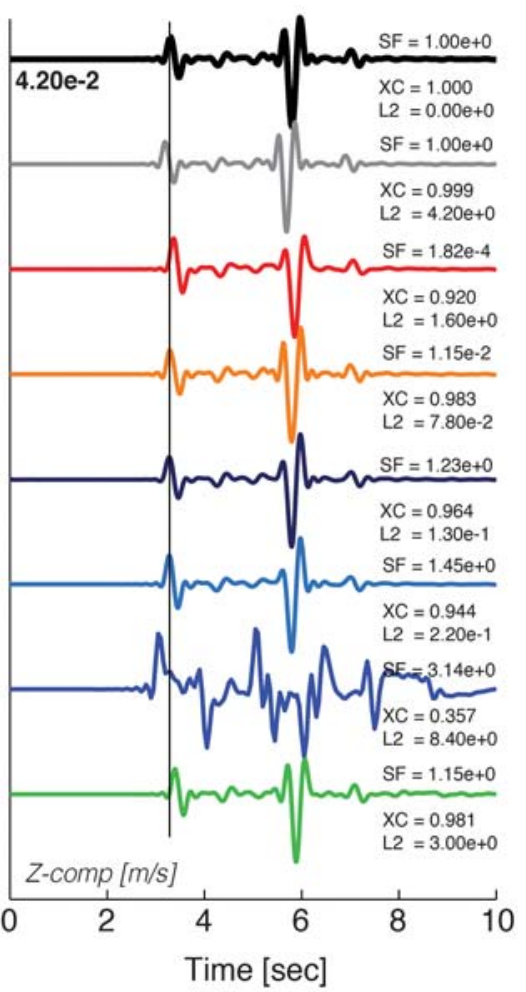

DG

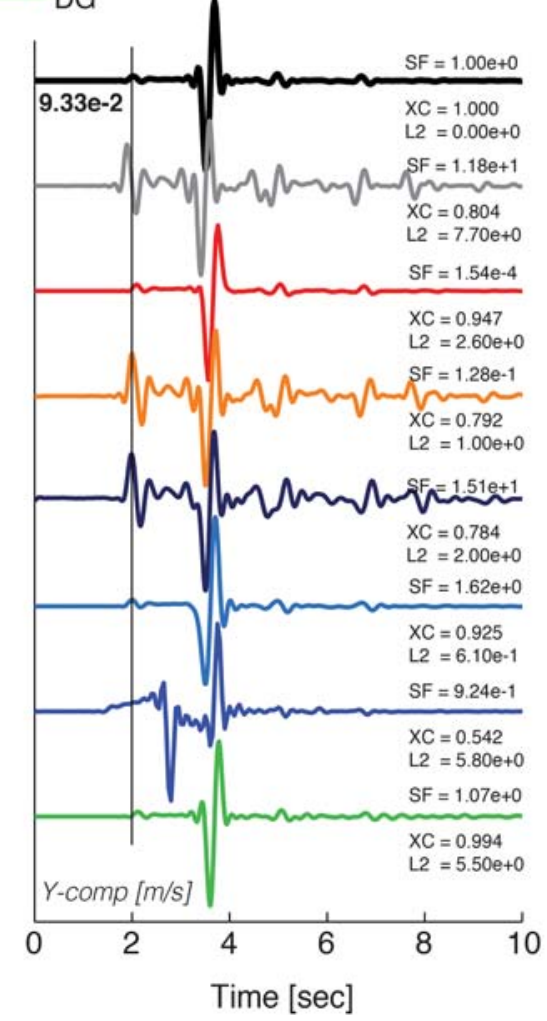

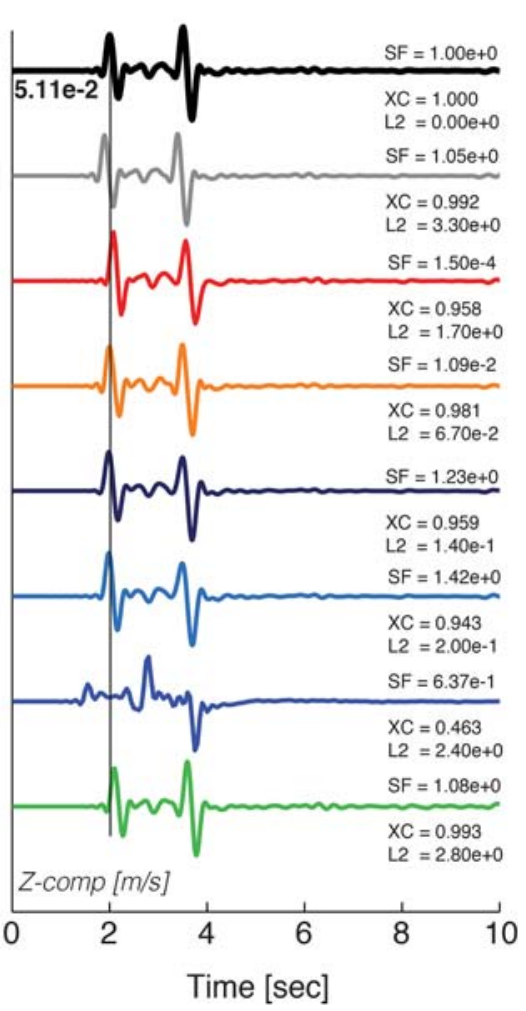

A Figure 2. (a) Three-component waveform comparison at site 10 (E) Fig. S1b) for the strike-slip point-source forward-modeling case. (b) Same as (a) for the dip-slip case at site 2 (E) Fig. S1c). Wave amplitudes are normalized by the indicated scale factor (SF) before computing the L2 norm (L2). Cross-correlation values (XC), scale factor, and L2 norm are calculated with respect to the selected reference (AX1; peak amplitude [in $\mathrm{m} / \mathrm{s}$ ] given in top left). Waveforms are aligned to hypocentral time, $t=0$. We observe an overall good visual agreement, with small time shifts but occasionally large-amplitude variations. Calculation CS3 used an incorrect input parameterization for the forward solver.

694 Seismological Research Letters Volume 87, Number 3 May/June 2016 

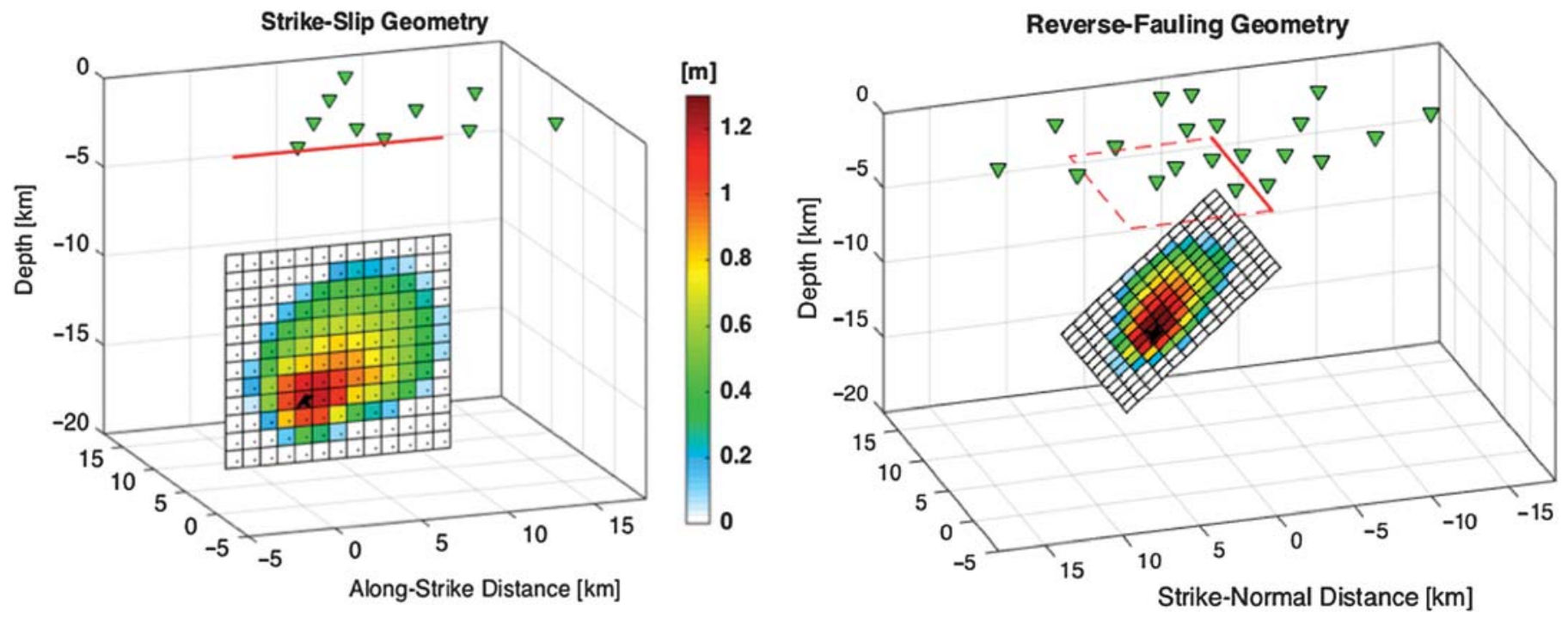

A Figure 3. Fault-receiver geometry and final slip on the fault for the extended-fault forward-modeling exercises: (left) strike-slip case, and (right) reverse-faulting case. Red lines mark the surface projection of the fault, black dots indicate locations on which the kinematic source parameters are specified, and green triangles mark the receiver locations (see also (E) Fig. S1b,c).

code parameterization or incorrect use of units, whereas phasearrival differences of a few samples are due to the particular implementation of the source time function. When filtering these synthetics to the frequency range typically used in source inversions $(0-1 \mathrm{~Hz})$, these timing issues become insignificant.

\section{Near-Source Extended-Fault Calculations}

Next, we consider two forward-modeling exercises for extendedfault ruptures that are specified in terms of $2 \mathrm{D}$ arrays of slip, rise time, and rupture-onset time over a planar fault surface. The strike-slip rupture occurs on a $12-\mathrm{km}$-long by $11-\mathrm{km}$-wide vertical fault, with seismic moment $M_{0}=1.66 \times 10^{18} \mathrm{~N} \cdot \mathrm{m}$ $\left(M_{\mathrm{w}}=6.11\right)$ and hypocentral depth $Z=14 \mathrm{~km}$. Slip and rise time are heterogeneous over the fault, the rupture-onset times at each point reflect variable rupture speed. The slip-rate function on each point of the fault is a boxcar. The thrust-faulting case is similar in dimension $(12 \mathrm{~km} \times 12 \mathrm{~km}$ fault plane $)$ and magnitude $\left(M_{0}=1.82 \times 10^{18} \mathrm{~N} \cdot \mathrm{m}, M_{\mathrm{w}}=6.14\right)$ and in kinematic rupture characteristics, but dips at an angle of $40^{\circ}$. Figure 3 displays the geometry and final slip on the fault for both cases. Station geometry and velocity-density structure are chosen identical to the point-source exercise (ㄹ) Fig. S1).

Similar to the point-source forward-modeling exercise, we observe differences in the provided solutions (Fig. 4), related mostly to variations in amplitude and frequency content. For the strike-slip case, waveforms agree well with each other, with cross-correlation coefficients typically above 0.88 (Fig. 4c). Pronounced differences in phase-arrival times are detectable in the dip-slip case for solution 5 (Fig. 4d), but for the other solutions amplitude variations of different wave packets result in crosscorrelation coefficients typically above 0.9 that increase to values $\sim 0.95$ after low-pass filtering (Fig. 4e). The flexible and fast online calculation and display of the root mean square (rms) misfit and cross-correlation-coefficient matrices (Fig. 4b-e) help to visually and quantitatively appreciate the differences between the individual solutions.

\section{Lessons Learned From Extended-Fault Forward-Modeling Tests}

The SIV forward-modeling exercises for near-source seismograms due to point-source and extended-fault ruptures reveal that the tested codes provide overall consistent results. However, we detect small phase-arrival time variations (for the point source) and significant amplitude differences (for both cases). Interestingly, in each case one forward-modeling solution is obviously incorrect, most likely due to a false input parameterization for the particular code used in that simulation.

Subtle variations in amplitude and phase-arrival times for the generally consistent solutions highlight the necessity that source inversion scientists be intimately familiar with the forward-modeling codes. Often, several code versions of the same method are available but may lead to slightly different results. Also, computer programs may have internal tuning parameters and/or require carefully chosen case-dependent parameter values. If these are not adequately specified, inaccurate results are expected. In addition, forward-modeling codes may not be comprehensively documented and/or researchers use them in an error-prone black-box mode. We therefore strongly advise source inversion researchers to conduct careful forwardmodeling tests and calibrations prior to the actual source inversion study. The SIV project provides appropriate forwardmodeling exercises, as well as an online platform for analyzing the results.

\section{INVERSION BENCHMARKS}

Three SIV inversion benchmarks have been defined so far: two for which only near-field seismograms are disseminated and 
(a)
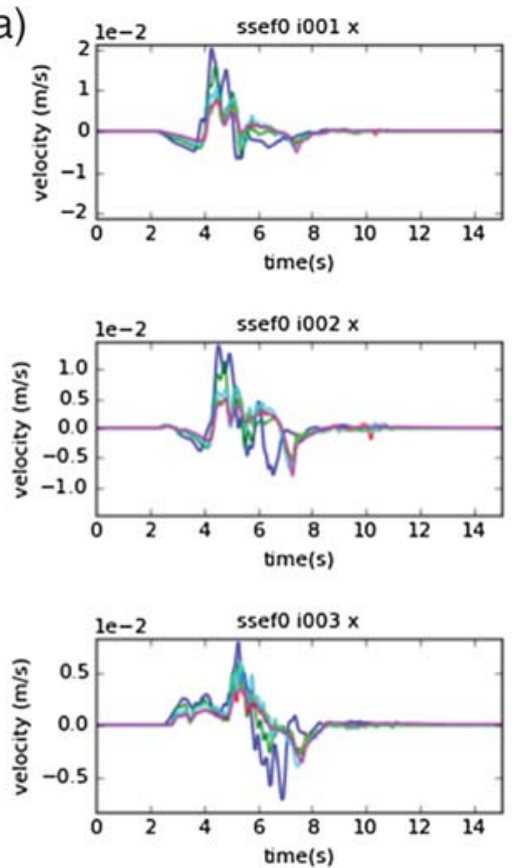

(b)

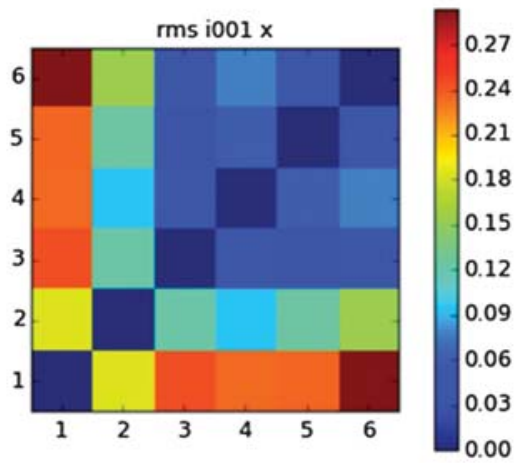

(c)

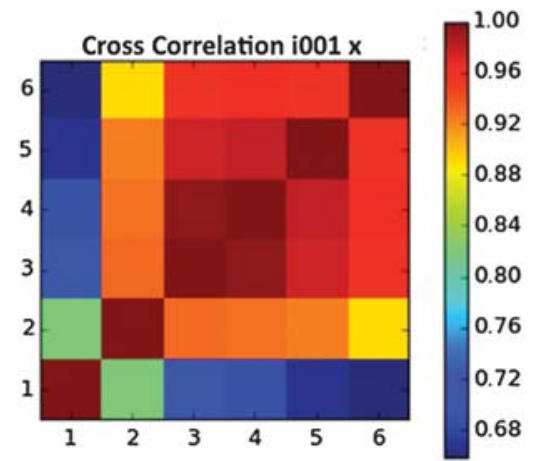

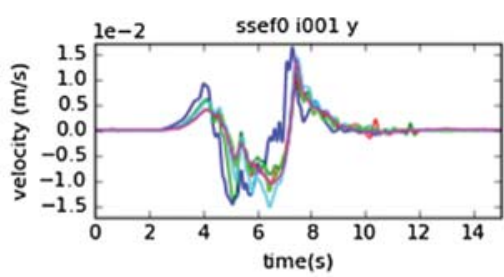
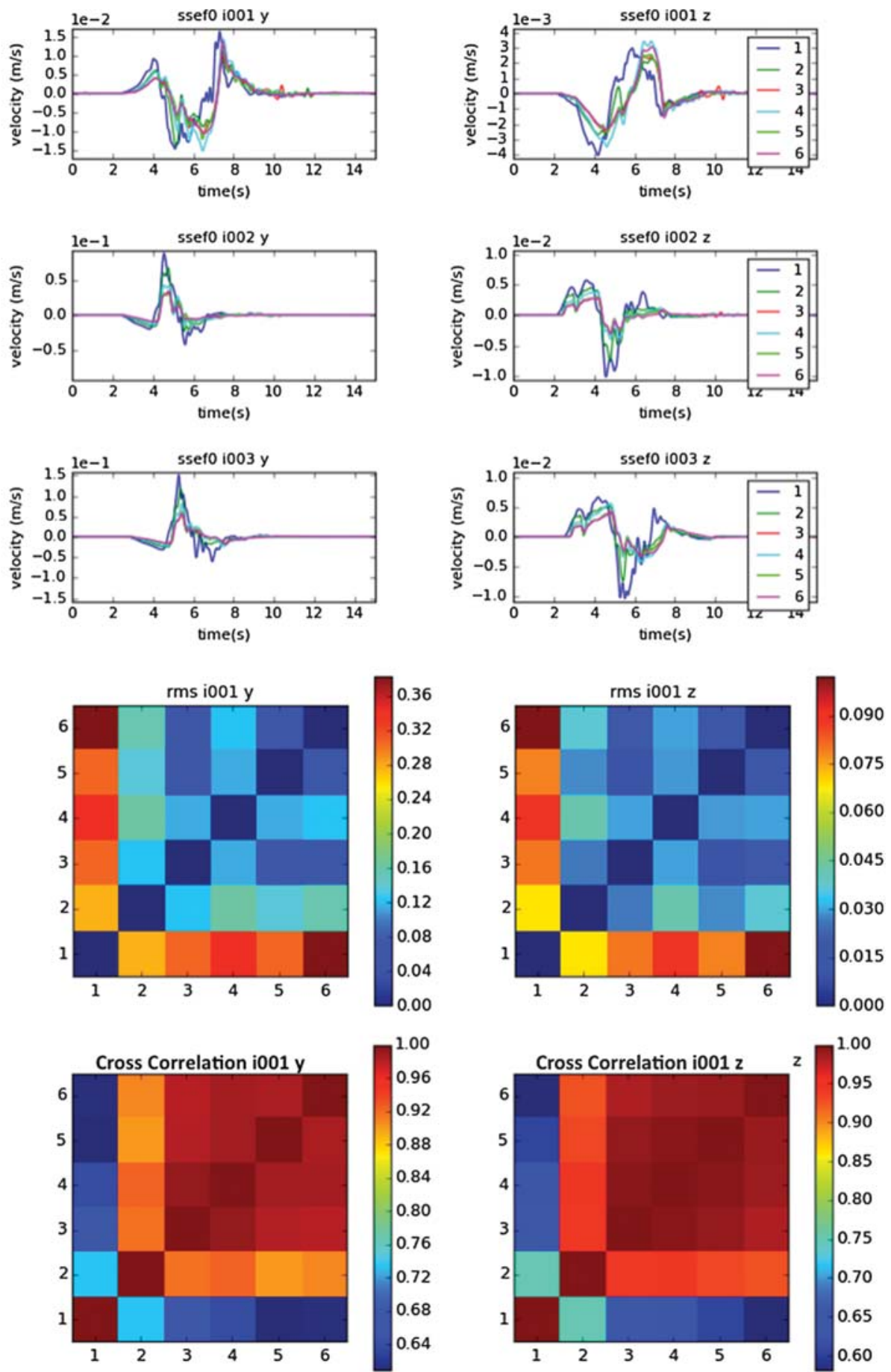

A Figure 4. Three-component waveform comparisons for the extended-fault forward-modeling exercises at selected stations (E) Fig. S1b). (a) Strike-slip case (slip model show in Fig. 3a) with six different modeling solutions at three sites. (b) Example for the root mean square (rms) misfit matrix for three-component waveforms at a single station. (c) Example for the cross-correlation coefficient matrix for three waveform components. (d) Dip-slip case (slip model shown in Fig. 3b) with horizontal waveforms at three locations and corresponding cross-correlation matrices. Notice the time shifts and high-frequency oscillations in solution 5. (e) Same as (d) after removing solution 5 from the analysis and low-pass filtering at $1 \mathrm{~Hz}$.

(Continued)

one for which teleseismic or GPS synthetics are also provided. A fourth benchmark is under development. All benchmarks have different characteristics and are summarized below.
The corresponding results and detailed statistical evaluation of the inversion solutions are described in the Statistical Analysis section. 

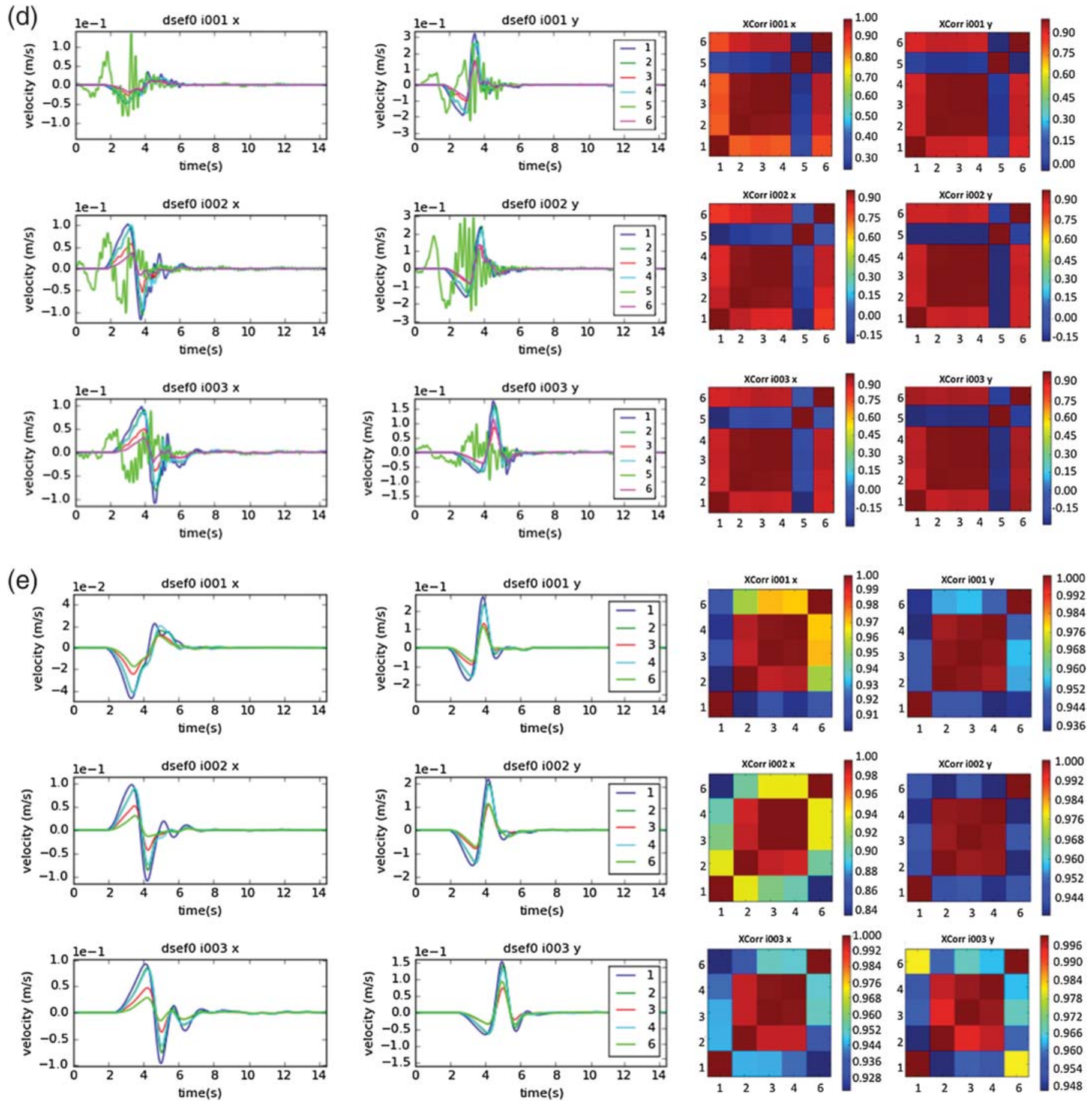

Figure 4. Continued.

\section{Benchmark inv1: A Strike-Slip Rupture on an $\mathbf{8 0}^{\circ}$ Dipping Fault}

The first inversion benchmark, invl, is based on a spontaneous dynamic rupture simulation for a strike-slip fault on an $80^{\circ}$ dipping fault plane. The initial stress conditions were chosen using heterogeneous initial shear stress, depth-dependent normal stress, and a slip-weakening length scale of $D_{c}=0.4 \mathrm{~m}$ that increased at the fault edges to a larger value $\left(D_{c}=2.0 \mathrm{~m}\right)$ to ensure smooth rupture termination. The velocity-density structure is identical to the one used in the forward-modeling exercises (ㅌ) Fig. S1). Near-fault seismograms $\left(f_{\max } \sim 2.5 \mathrm{~Hz}\right)$ were computed at 56 sites, but data were distributed for only 40 sites. The modeling teams had to blind-predict the seismograms at the remaining 16 locations. Figure 5 displays the fault-receiver geometry and final peak slip-rate and final slip distributions. The seismic moment of the event is $M_{0}=1.06 \times 10^{19} \mathrm{~N} \cdot \mathrm{m}$ 
(a)

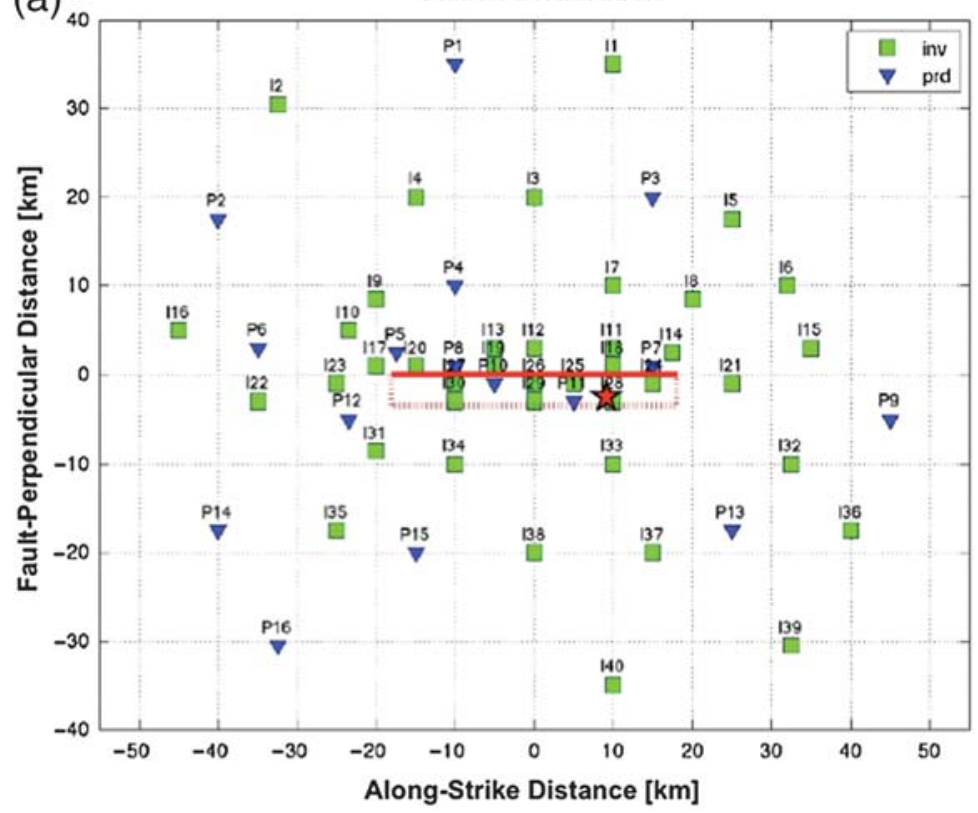

(b)
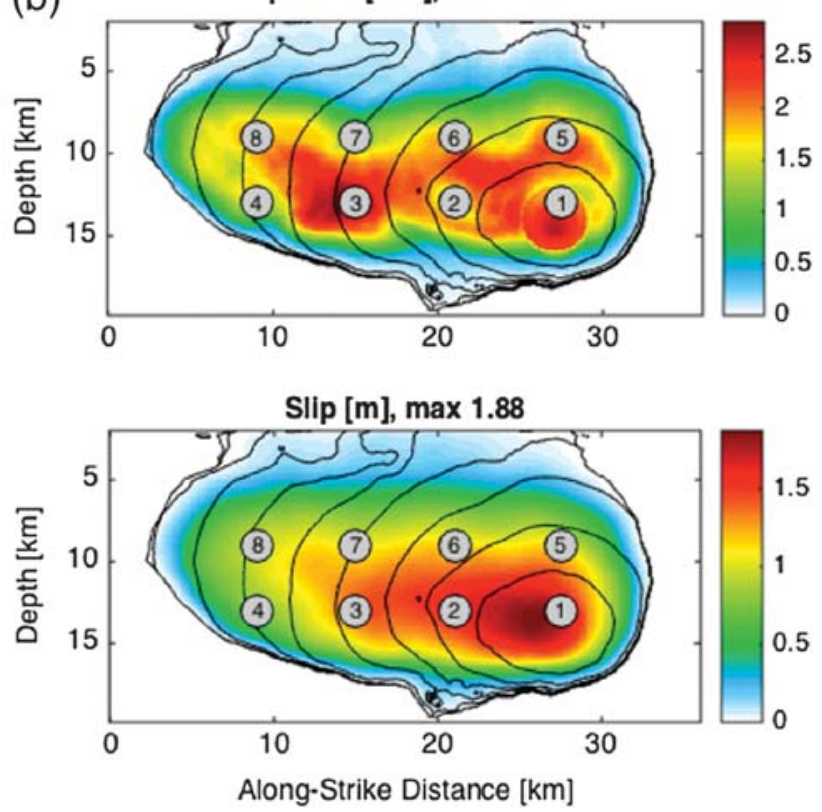

A Figure 5. (a) Source-receiver geometry for SIV benchmark inv1. Red lines mark the surface projection of the fault, and the star indicates the epicenter. Green symbols denote sites for which synthetic data are distributed, blue symbols indicate sites for which blindpredicted waveforms are requested. (b) Rupture model for the inv1 benchmark, resulting from a spontaneous dynamic rupture calculation with heterogeneous initial stress. The top panel shows the final peak slip-rate (in $\mathrm{m} / \mathrm{s}$ ), and the bottom panel shows the final slip (in $\mathrm{m}$ ). The black contour lines mark the rupture progression in $1 \mathrm{~s}$ intervals. For the marked gray points, labeled $1-8$, the resulting dynamic slip-rate functions are displayed in (E) Figure S2, indicating a Yoffe-type functional form.

$\left(M_{\mathrm{w}}=6.6\right)$, occurring on an $\sim 30-\mathrm{km}$-long and $\sim 15-\mathrm{km}$ wide fault.

The problem description for this first benchmark exactly specifies all metadata (velocity structure, magnitude, hypocenter location, and fault geometry). These are unknown in real applications. Thus, the invl benchmark, without noise on the synthetics or metadata uncertainties, represents an idealized case. However, the dynamic rupture calculation returned Yoffe-type local slip-rate functions (ㅌ) Fig. S2; e.g., Tinti et al., 2005) that are difficult to resolve using a simple parametric (e.g., boxcar or triangular) slip-rate representation. This could be approximated using a more flexible source time function representation (e.g., multiple time windows or an asymmetric cosine-type function).

\section{Benchmark inv2: Normal-Faulting Ruptures on Shallow- Dipping Faults}

In this benchmark, we include two different rupture scenarios with identical source-receiver geometry and background velocity structure (ㅌ) Fig. S1). However, inv $2 a$ and $i n v 2 b$ are different, because synthetic seismograms for $i n v 2 b$ are computed in a 3D heterogenous velocity model with correlated-random wavespeed variations overlain over the 1D background model. The resulting seismic scattering leads to amplitude changes, waveform distortions, and phase-arrival time differences compared with the background structure of inv2a (Imperatori and Mai, 2013).
(E) Figure $S 4$ illustrates the source-receiver geometry and input finite-fault rupture model used to compute near-source synthetic seismograms $\left(f_{\max } \sim 3 \mathrm{~Hz}\right)$. The normal-faulting scenario earthquake $\left(M_{\mathrm{w}}=7.0\right)$ occurs on a $45^{\circ} \pm 5^{\circ}$ dipping fault with $90^{\circ}$ strike, hypocentral depth $Z=10 \pm 1 \mathrm{~km}$, and slip direction (rake) of $240^{\circ} \pm 10^{\circ}$. Thus, these scenarios are characterized by uncertain metadata. This allows assessment of how the different teams capture imprecise parameter specifications that emulate uncertainties for real earthquakes. The rupture plane is about $40 \mathrm{~km} \times 20 \mathrm{~km}$, and the rupture process is prescribed with heterogeneous slip, variable rise times that correlate with the slip pattern, and varying rupture speed (ㅌ) Fig. S4, adapted after Imperatori and Mai, 2012).

\section{Benchmark inv3: A Large Hypothetical Earthquake in Southern California}

The kinematic rupture model represents a large hypothetical strike-slip earthquake in southern California, with spatial variability in slip, rise time, and rupture speed, and some geometrical fault complexity. Results for inv3 are not yet available because the synthetic datasets have just been released. In particular, far-field (teleseismic) synthetics are provided at 52 azimuthally well-distributed locations at a distance range of $30^{\circ}-90^{\circ}$, computed within the $1 \mathrm{D}$ radial-symmetric Earth model AK135. We generate ray-theory $P$ - and $S H$-wave seismograms of $140 \mathrm{~s}$ duration, as typically used in teleseismic source inversion studies. For comparison and further work, we also compute complete far-field seismograms using two alternative approaches 

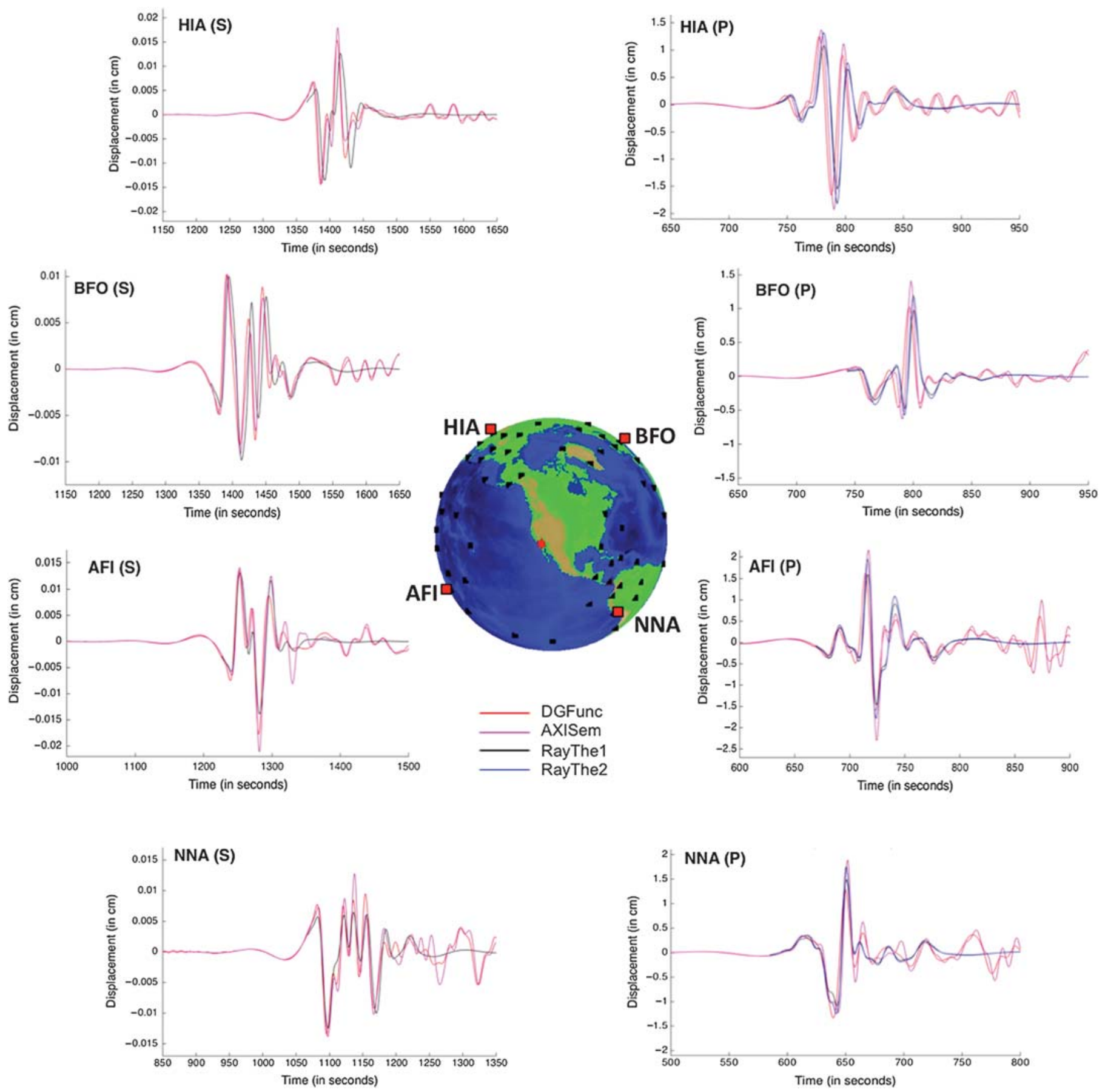

A Figure 6. Example of teleseismic waveforms for inversion benchmark inv3 at four stations. The red star marks the epicenter. $S H$ waveforms are shown on the left and $P$-wavetrains are on the right. Synthetics are computed using the direct Green's function method (DGFunc; Friederich and Dalkolmo, 1995), an axisymmetric spectral-element method (AXIsem; Nissen-Meyer et al., 2014; van Driel et al., 2015), and two implementations of a global ray-theory approach (RayThe1 and RayThe2; Kikuchi and Kanamori, 1991). The first two methods provide the complete seismic wavefield for a spherically layered isotropic Earth.

(Kikuchi and Kanamori, 1991; Friederich and Dalkolmo, 1995; Nissen-Meyer et al., 2014; van Driel et al., 2015). Figure 6 shows example waveforms and the station distribution for the inv3teleseismic synthetic data.

Near-source strong-motion synthetics are computed in a 3D Earth model of southern California (SCEC CVM4;
Kohler et al., 2003) with a generalized finite-difference method (Ely et al., 2008). The near-surface velocity structure is truncated to a minimum shear wavespeed of $620 \mathrm{~m} / \mathrm{s}$, therefore $f_{\max } \sim 1 \mathrm{~Hz}$. Near-field synthetics are provided for a dense station network with an interstation spacing on the order of $20 \mathrm{~km}$. Figure 7 depicts the near-source receiver geometry 


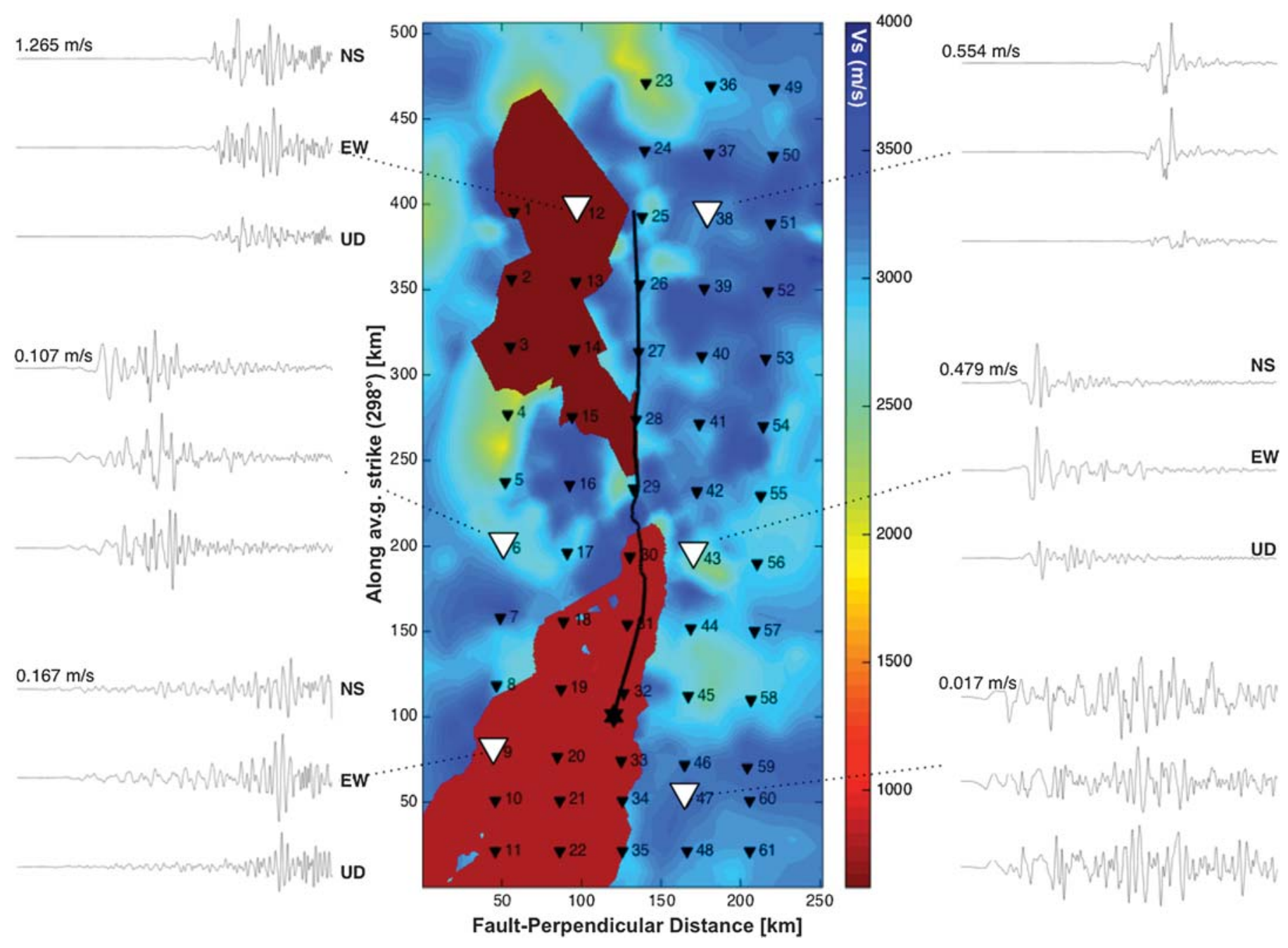

- Figure 7. Map view of rupture geometry and near-fault receivers for inversion benchmark inv3. The star marks the epicenter, and the color coding reflects the shear-wavespeed at the Earth's surface. Three-component synthetic seismograms at selected stations reveal effects of directivity and 3D Earth structure. In each seismogram panel, we plot (from top to bottom) north-south, east-west, and the vertical component velocity seismogram, normalized with respect to peak absolute amplitude of all three components at that location (shown in $\mathrm{cm} / \mathrm{s}$ ).

for the inv 3 benchmarks and shows example near-field synthetics at selected stations. In this benchmark, source inversion teams may adopt the specified 3D Earth structure in their inversion or use an appropriately simplified velocity-density structure. The later analysis of inversion solutions and data predictions will illustrate the effects of the assumed velocity-density structure on source-model uncertainties (e.g., Razafindrakoto and Mai, 2014; Gallovic et al., 2015).

\section{Forthcoming Benchmarks}

Forthcoming source inversion benchmarks are built on the experience gleaned from the inv1-inv 3 exercises. They will include additional intricacy, in particular in terms of 3D Earth structure (including topography) and geometrical rupture complexity. Computing the synthetic datasets at the required resolution such that they contain relevant information about the space-time rupture evolution will require substantial computational resources, modern high-performance computing (HPC)-architecture, and advanced numerical forward solvers.

We also plan to provide additional datasets that help to estimate earthquake source processes. Recently, backprojection imaging has been successfully applied to track the rupture evolution in space and time (e.g., Ishii et al., 2005; Krüger and Ohrnberger, 2005; Koper et al., 2011; Meng et al., 2011, 2012; Kiser and Ishii, 2012; Fan and Shearer, 2015). However, it is still unclear how exactly the backprojected image relates to kinematic rupture properties (e.g., fault slip), because it utilizes primarily the high-frequency seismic wavefield (typically $f \sim 1 \mathrm{~Hz}$ ). Recent work attempts to generalize the backprojection technique and to incorporate it into linear inversions (Zhang et al., 2014). Dedicated benchmark exercises may help relate backprojection to finite-fault inversions to more comprehensively characterize the underlying rupture process. For future SIV benchmarks of large subduction-earthquake scenarios, we may also provide synthetic tsunami waveform data, which are used to constrain slip on the 
fault (e.g., Satake et al., 2013). In addition, synthetic Interferometric Synthetic Aperture Radar (InSAR) data may be included, because these help to constrain fault geometry, fault slip, and seismic moment (e.g., Jónsson et al., 2002). By providing multiple datasets for a single SIV benchmark, we will test how different data-weighting schemes affect the inversion solutions.

\section{STATISTICAL ANALYSIS}

Our goal is to statistically evaluate how well the SIV solutions reproduce the synthetic data and the input rupture model. We use common waveform misfit measures (L1 norm, L2 norm, variance reduction, cross-correlation coefficient), as well as time-frequency envelope misfits and time-frequency phase misfits (Kristekova et al., 2009). Quantitatively comparing 2D fields of rupture parameters (e.g., slip, rupture time, rise time) requires defining adequate misfit measures. Mai et al. (2007) used the 2D cross-correlation coefficient and the power-spectral decay of slip. For the SIV inversion solutions, we apply the spatial-prediction comparison test to the slip models (Zhang et al., 2015) and the multidimensional scaling (MDS) approach of Razafindrakoto et al. (2015). These methods implement dissimilarity quantification between two physical fields (e.g., slip models) and allow for ranking these fields with respect to a chosen reference. If the true model is known, one can define metrics to discriminate between "excellent" solutions and "good," "fair," or "poor" solutions (Razafindrakoto et al., 2015). For further details, we refer the reader to the corresponding publications. Below, we describe inversion results and their statistical analysis for benchmark exercise inv1 and briefly summarize the outcome of benchmark inv2a.

\section{Statistic for Benchmark Exercise inv1}

Figure 8 displays a graphical comparison of four rupture-model solutions (Fig. 8b-e), showing slip, rupture-onset time, and rise time, with respect to the known target model (Fig. 8a). The slip maps in Figure $8 \mathrm{~b}$ and $8 \mathrm{c}$ look similar to the input model (Fig. 8a), whereas the slip maps in Figure 8d and 8e reveal different spatial patterns. The same applies to rupture-onset time and rise time. Remarkably, all three-component waveforms are very similar (ㅌ) Fig. S3a), with acceptable rms misfit values (ㅌ) Fig. S3b) and high cross-correlation coefficients (typically above 0.85 ; () Fig. S3c). This illustrates that waveform misfit measures are not necessarily diagnostic of model error.

To further examine rupture-model similarities, the SIV platform provides a summary table of scalar source-parameter metrics (ㅌ) Table S1) that list seismic moment, maximum slip, different source-dimension measures, and the slip centroid. Note that consistency in the macroscopic scalar source parameters between the various models does not imply an agreement in the corresponding spatial distribution of slip. A first-order qualitative appraisal for rupture-model similarity can be gleaned from contour plots of rupture area, slip, rupture-onset time, and rise time (Fig. 9). For benchmark inv1, the ruptureonset times agree quite well for about the first $3 \mathrm{~s}$ of the rupture but start deviating subsequently.
Ranking rupture-model solutions with respect to each other, or with respect to a known solution, requires statistically robust misfit measures. Zhang et al. (2015) developed and tested several misfit measures for earthquake slip models using the spatial-prediction comparison test (SPCT, Hering and Genton, 2011), in which a chosen loss function quantifies the error between two 2D fields. Zhang et al. (2015) calibrated the SPCT approach by testing various loss functions (squarederror loss [SE], absolute-error loss [AE], and correlation skill $[\mathrm{CK}])$ that are sensitive to different spatial correlation lengths or different heterogeneity levels of slip. Their analysis shows that the SPCT method provides an effective tool to quantitatively rank slip models. Razafindrakoto et al. (2015) applied the above loss functions to an MDS approach to further compare and rank rupture models. Their work shows the ability of the SPCT and MDS methods to classify slip models even if a true reference solution does not exist. Applying the MDS approach to 20 published rupture models for the 2011 Tohoku earthquake demonstrates quantitatively how different data types affect the final slip distribution (Razafindrakoto et al., 2015).

The outcome of the MDS approach for inv1 benchmark is shown graphically (Fig. 10) and in tabulated format (ㅌ) Table S2) for dissimilarity values computed using the normalized SE. Based on calibrated test results, Razafindrakoto et al. (2015) propose that a normalized dissimilarity value $<5$ indicates an "excellent" agreement between two slip models. A "good" agreement is found if this value falls in the 5-20 interval, the 20-40 range indicates a "fair" agreement, and beyond the agreement is "poor." Applying these definitions to solutions of benchmark inv 1 and choosing the known target solution as the reference, we find that solution $f_{s g}$ is best, obtained using a new frequencydomain inversion approach (Fan et al., 2014), resulting in the smallest dissimilarity value (ㅌ) Table S2). Solution gallovic2 ranks second best. These two solutions are shown in Figure 8b,c for a visual comparison of the slip patterns.

Many proposed solutions fall in the category "good," indicating consistency between the inferred and known slip distribution (Fig. 10). In this example, the "best model" is determined using the selected MDS metric (SE). Choosing the AE or CK may return a different ranking. Note that this ranking does not account for other rupture properties (rise time; rupture-onset time) or waveform misfit.

\section{Statistic for Benchmark Exercise inv2a}

We encourage the reader to apply the online comparison tools of the SIV platform to benchmark exercise inv2a. Examples are given in (E) Figures $S 5$ and $S 6$, which show rupture-model solutions, scalar source-model parameters, and a selection of seismic waveforms. For inv1, variations are observed in seismic moment by a factor $\sim 1.5$ and in maximum slip by a factor $\sim 7$. Solutions for inv2a appear to be more similar (factor $\sim 1.4$ in seismic moment, factor $\sim 4$ in maximum slip). Ranking the solutions is not possible based on these macroscopic source parameters or using the apparent waveform similarity (ㅌ) Fig. S6b). As for the inv1 case, the inv2a benchmark demonstrates that good waveform fitting can be achieved despite remarkably different rupture 
(a)
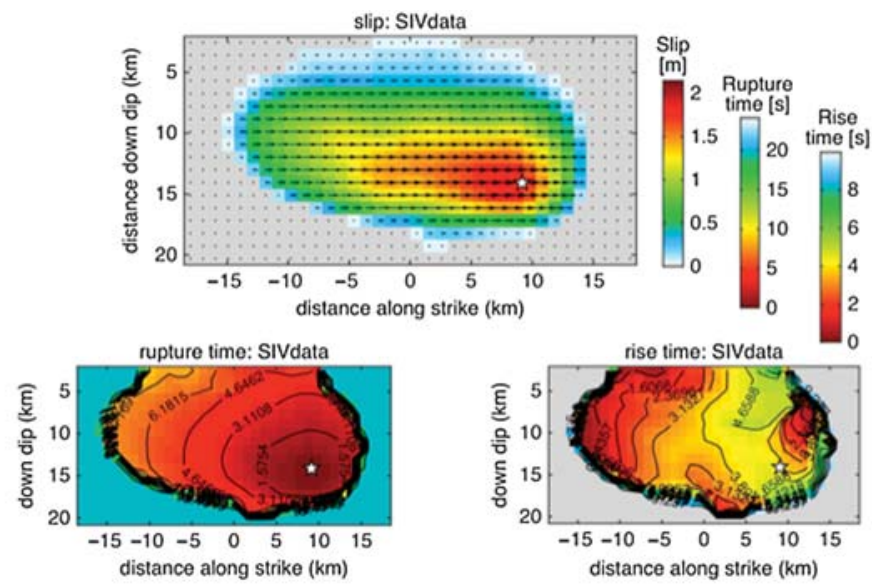

(b)
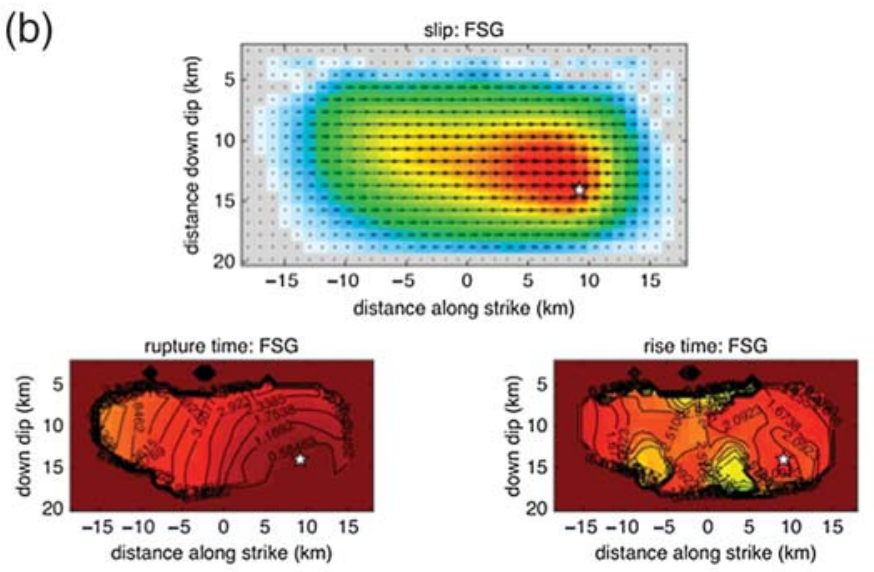

(d)
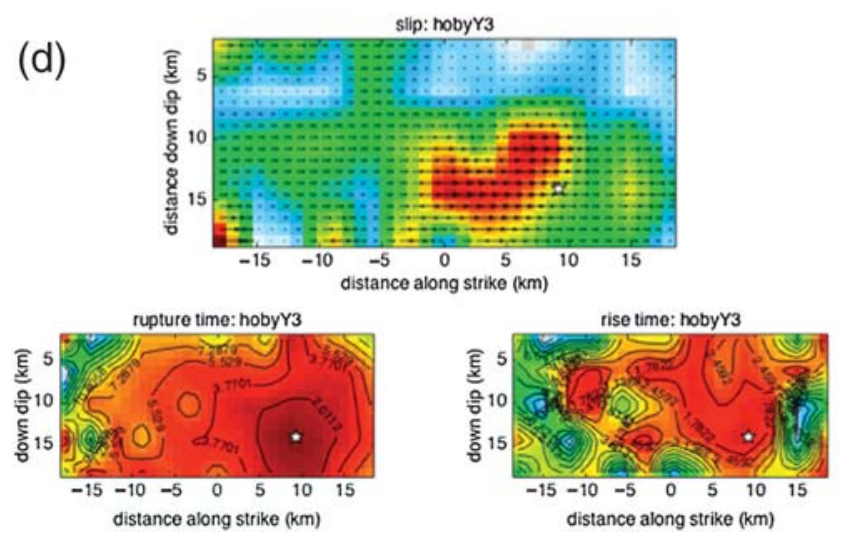

(c)
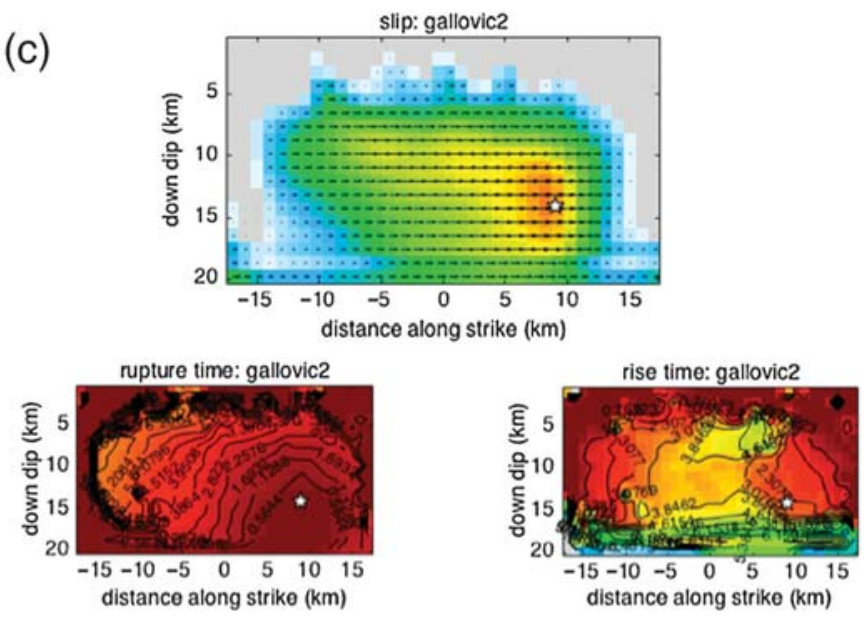

(e)
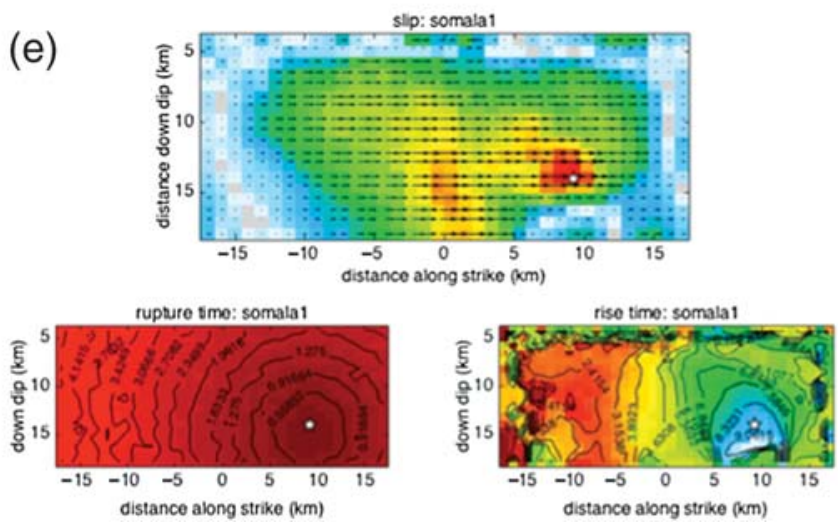

A Figure 8. Slip-inversion results for benchmark inv1. The input model is given in (a), inversion solutions are shown in (b)-(e) in terms of final slip (top), rupture time (bottom left), and rise time (bottom right). The color scale for each source parameter, shown in (a), is identical for the five rupture models. The white star marks the hypocenter. Note that the actual fault-plane dimensions may not be identical because these had to be chosen by the modeling teams.

models. Applying the MDS approach outlined above to these solutions, we find that only four models fall in the "good" category (ㅌ) Fig. S6c,d), but it is clear that two solutions, asano and gallovicl, clearly outperform the other solutions. An alternative approach to compare the complete spatial-temporal rupture propagation by exploiting the eigenstructure of the inverse problem is proposed by Gallovič and Ampuero (2015).

\section{SUMMARY, RECOMMENDATIONS, AND FUTURE GOALS}

The SIV collaboration continues its activities, gathering insight on how to optimally conduct earthquake source inversions and to properly test and quantify their resolving power. The SIV tests reveal that even the computation of synthetic seismograms 

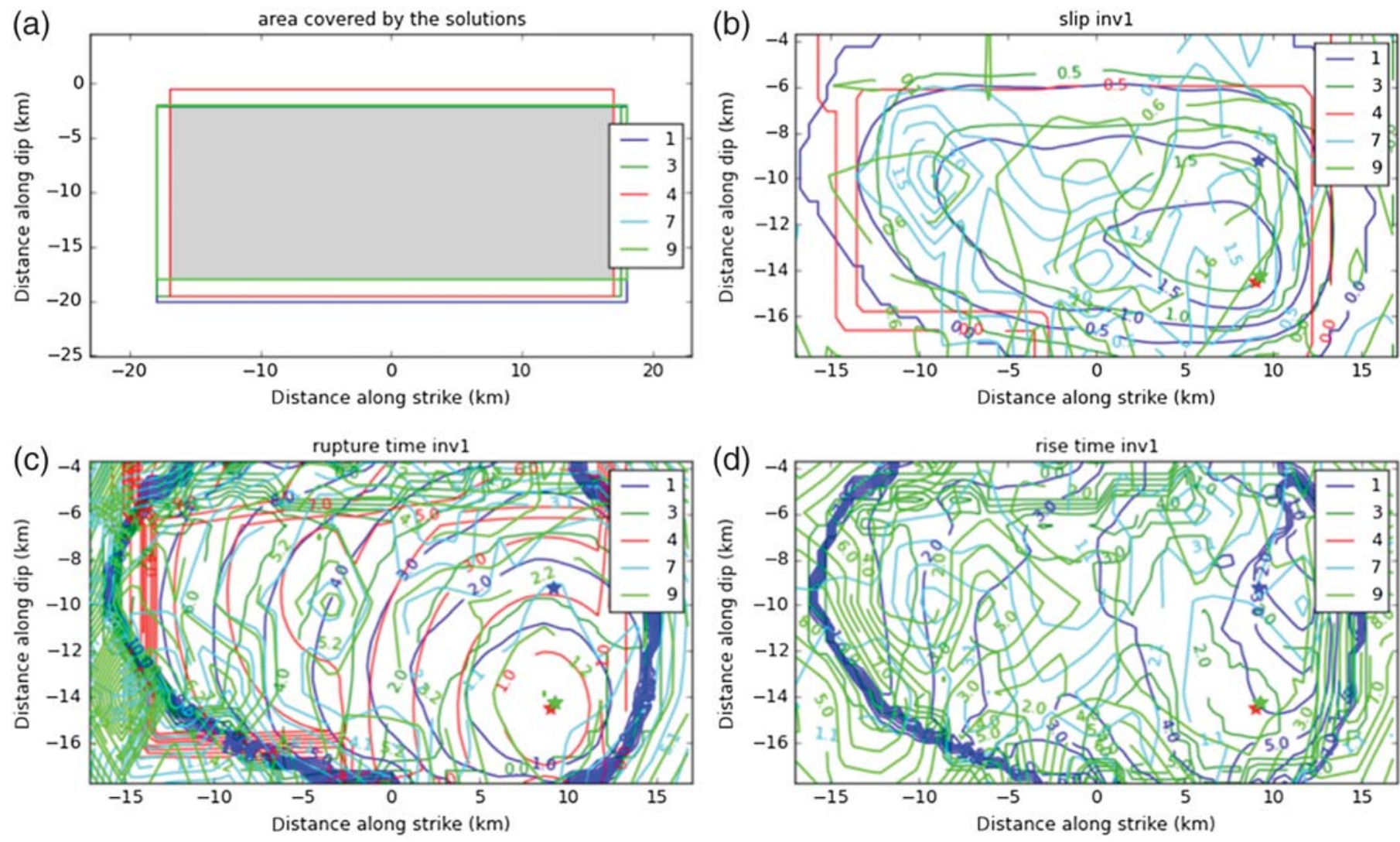

A Figure 9. Graphical overlay comparison of rupture-model solutions for inv1 shown in Figure 8. The true model is 1. The overlay contour plots show (a) the occupied fault area, (b) slip contours, (c) rupture-time contours, and (d) rise-time contours, using a common spatial sampling of $3 \mathrm{~km} \times 3 \mathrm{~km}$ subfault size. These contour plots are generated using the visualization tool available on the SIV platform (see Data and Resources).

for a point source or precisely specified finite-fault rupture is error prone. Although validated computer programs generally generate consistent results, inadvertently choosing slightly incorrect input parameters for a given code may jeopardize the forward simulations. Many codes are poorly documented (if at all), and/or hidden parameters in the code require tuning for a given problem. However, users are often not the code authors and may treat them as "black boxes," without knowing about the inner workings of the forward-modeling engine and its potential problems. Therefore, we recommend that any sourcemodeler verifies and tests the chosen forward-modeling code with respect to published solutions. The SIV effort provides such benchmark tests. We also recommend testing new slip inversion methods using the SIV benchmarks.

The inversion results for benchmarks inv1 and inv2a document that an excellent waveform fit (quantified by small rms misfit values) does not guarantee a good recovery of the "true" rupture model. Significantly different kinematic source models may explain the data equally well. At this point, we have not investigated the potential influence of a chosen misfit function for a particular inversion method. However, we find that the inversion methods proposed by Gallovic et al. (2015) and Fan and Shearer (2015) perform particularly well. Common to both methods is that these regularized linear inversions are un- constrained in the temporal rupture evolution. The functional form of the local on-fault slip-rate function is not prescribed, and there is no assumption on rupture speed. Instead, the rupture is allowed to develop in space and time as preferred by the data, with adequately dense temporal sampling to recover the local slip-rate function. Given our current test results, these types of methods appear as being best suited to estimate the spatiotemporal rupture evolution from near-fault data such that subsequent inferences can be made on the dynamic rupture process. However, further tests are needed to confirm this conjecture, including, for instance, benchmarks with complex rupture geometry in 3D Earth structure. Furthermore, including backprojecting imaging into the linear inversion (Zhang et al., 2014) may provide a promising path forward. In future benchmarks, we plan to supply additional synthetic datasets (GPS; InSAR, tsunami data for a subduction-zone benchmark) to also test joint inversion strategies and corresponding dataweighting schemes.

We describe an approach to quantify the goodness of fit of inverted rupture models with respect to an input model, based on statistical analyses using the SPCT (Hering and Genton, 2011; Zhang et al., 2015). This approach is extended to rank the solutions using MDS (Razafindrakoto et al., 2015). Alternative methods for statistical quantification of rupture-model 


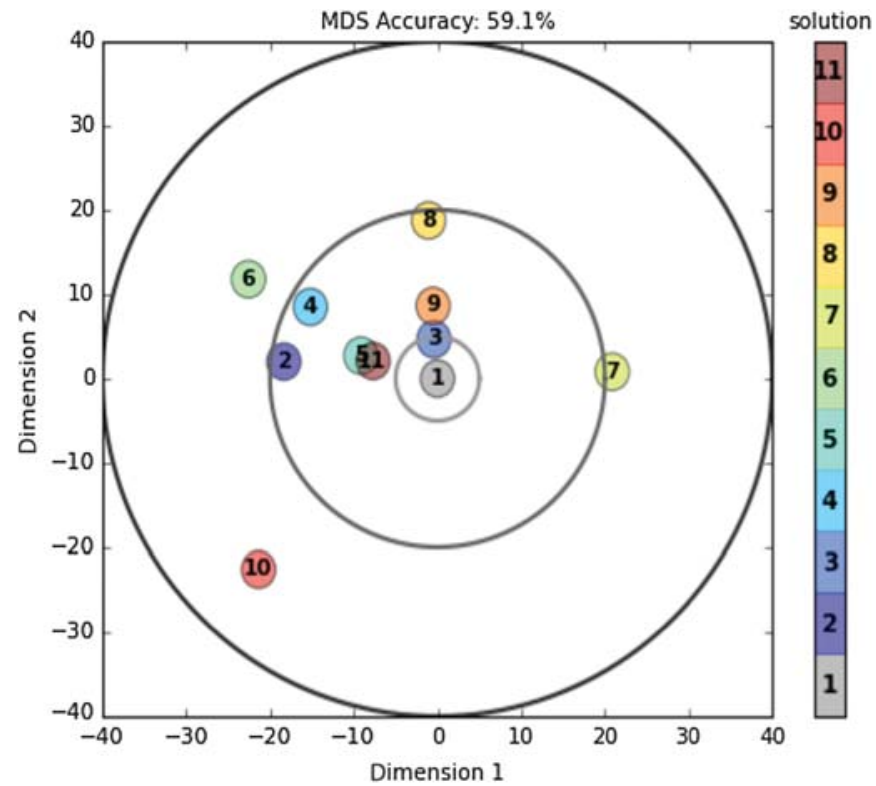

\begin{tabular}{|c|c|c|c|}
\hline \multicolumn{4}{|c|}{ Ranking with respect to the reference } \\
\hline Excellent & Good & Fair & Poor \\
\hline $\begin{array}{l}\text { SIVdata (1) } \\
\text { fsg (3) }\end{array}$ & $\begin{array}{l}\text { causse (2) } \\
\text { gallovic (4) } \\
\text { gallovic2 }(5) \\
\text { hobyy1 }(8) \\
\text { hobyy3 (9) } \\
\text { somala1 (11) }\end{array}$ & $\begin{array}{l}\text { gallovic3 (6) } \\
\text { hobyt (7) } \\
\text { somala (10) }\end{array}$ & \\
\hline
\end{tabular}

A Figure 10. Rupture-model statistic for benchmark exercise inv1, showing the multidimensional scaling (MDS) analysis for all inv1 solutions with respect to the target, "SIVdata" (indicated by model 1). The classification of the solutions follows Razafindrakoto et al. (2015). Symbols located in the center of the MDS graph indicate an excellent fitting model (e.g., fsg, solution 3). Corresponding dissimilarity values are given in (E) Table S2.

(dis)similarities are given by Barrall and Harris (2015) or Gallovic and Ampuero (2015). Inspired by the SIV benchmark results, the latter study proposes to exploit the eigenstructure of the inverse problem. In the end, a combination of various approaches may best quantify similarities and differences in rupture models such that we can conclusively extract the strength and limitations of the underlying method, data, or chosen parameterization for the source inversion problem.

It is also important to note that agreed-upon standards for documenting finite-fault earthquake rupture models are needed to facilitate statistical analysis and seismological research using source inversion results. Mai et al. (2016) propose a common rupture-model format and describe the required level of detail for documenting the inversion method, the data used, the parameterization, and metadata. If such standards are adhered to, transparency and reproducibility of finite-fault inversions is ensured, lending further credibility to earthquake source inversion studies. For the SIV benchmarks, a more compact rupture-model format has been adopted for simplicity, but the long-term SIV goal is to develop avenues for reproducible, testable, perhaps even (semi)automated finite-fault inversions. As such, we envi- sion a prospective testing center in which various earthquakesource inversion codes run side by side on a range of test problems first and then on real data, with minimal user intervention, to generate finite-fault rupture models with properly quantified uncertainties. The SIV efforts described in this article are a first step in this direction.

\section{DATA AND RESOURCES}

The earthquake rupture models shown in Figure 1 are taken from the online finite-fault earthquake source models (SRCMOD), available at http://equake-rc.info/srcmod (last accessed November 2015). All Source Inversion Validation (SIV) benchmarks and related problem descriptions, data, and metadata, as well as plotting and analysis routines, can be accessed via the SIV database (http://equake-rc.info/SIV/, last accessed December 2015). The contour plots in Figure 9 are generated using the visualization tool available on the SIV platform (http:// equake-rc.info/SIV/sivtools/list_solutions_for_benchmark/inv1/). Slip-heterogeneity characterizations are based on source models of past earthquakes, including an unpublished manuscript by K. K. S. Thingbaijam and P. M. Mai, "Evidence for truncated exponential distribution of earthquake slip." $\mathbf{<}$

\section{ACKNOWLEDGMENTS}

We thank Juerg Hauser for developing the initial Source Inversion Validation (SIV) benchmark platform. Constructive criticism by and inspiring discussion with Ralph Archuleta, Greg Beroza, Bill Ellsworth, Chen Ji, Ruth Harris, Thorne Lay, Lingsen Meng, Peter Shearer, and others helped to steer the SIV initiative. Constructive criticism by three anonymous reviewers helped to improve the manuscript. We are grateful to the $S R L$ editorial staff for their support and guidance. This research was supported by the Southern California Earthquake Center (Contribution Number 6159). Southern California Earthquake Center (SCEC) is funded by National Science Foundation (NSF) Cooperative Agreement EAR-1033462 and U.S. Geological Survey (USGS) Cooperative Agreement G12AC20038. F. G. was supported by the Czech Science Foundation project 14-04372S. This study is also funded by King Abdullah University of Science and Technology (KAUST), Thuwal, Saudi Arabia. Earthquake-rupture simulations were carried out using the KAUST Supercomputing Laboratory (KSL), and we acknowledge support by KSL staff.

\section{REFERENCES}

Aki, K., and P. Richards (2002). Quantitative Seismology, Second Ed., University Science Books, Sausalito, California.

Archuleta, R. J. (1984). A faulting model for the 1979 Imperial Valley earthquake, J. Geophys. Res. 89, 4559-4586, doi: 10.1029/ JB089iB06p04559.

Asano, K., T. Iwata, and K. Irikura (2005). Estimation of source rupture process and strong ground motion simulation of the 2002 Denali, Alaska, earthquake, Bull. Seismol. Soc. Am. 95, 1701-1715. 
Barall, M., and R. A. Harris (2015). Metrics for comparing dynamic earthquake rupture simulations, Seismol. Res. Lett. 86, 223-235, doi: $10.1785 / 0220140122$.

Beresnev, I. A. (2003). Uncertainties in finite-fault slip inversions: To what extent to believe? (A critical review), Bull. Seismol. Soc. Am. 93, 2445-2458.

Bernauer, B., A. Fichtner, and H. Igel (2014). Reducing non-uniqueness in finite source inversion using rotational ground motions, J. Geophys. Res. 119, 4860-4875, doi: 10.1002/2014JB011042.

Blaser, L., F. Krüger, M. Ohrnberger, and F. Scherbaum (2010). Scaling relations of earthquake source parameter estimates with special focus on subduction environment, Bull. Seismol. Soc. Am. 100, 2914-2926.

Bouchon, M. (1981). A simple method to calculate Green's functions for elastic layered media, Bull. Seismol. Soc. Am. 71, 959-971.

Bouchon, M. (1997). The state of stress on some faults of the San Andreas system as inferred from near-field strong motion data, J. Geophys. Res. 102, 11,731-11,744.

Bouchon, M., H. Karabulut, M.-P. Bouin, J. Schmittbuhl, M. Vallée, R. Archuleta, S. Das, F. Renard, and D. Marsan (2010). Faulting characteristics of supershear earthquakes, Tectonophysics 493, 244-253, doi: 10.1016/j.tecto.2010.06.011.

Bouchon, M., M. N. Toksoz, H. Karabulut, M. P. Bouin, M. Dietrich, M. Aktar, and M. Edie (2002). Space and time evolution of rupture and faulting during the 1999 Izmit (Turkey) earthquake, Bull. Seismol. Soc. Am. 92, 256-266.

Causse, M., F. Cotton, and P. M. Mai (2010). Constraining the roughness degree of slip heterogeneity, J. Geophys. Res. 115, no. B05304, doi: 10.1029/2009JB006747.

Causse, M., L. A. Dalguer, and P. M. Mai (2013). Variability of dynamic source parameters inferred from kinematic models of past earthquakes, Geophys. J. Int. 196, 1754-1769.

Coutant, O. (1989). Program of numerical simulation AXITRA, Research Reports LGIT, Université Joseph Fourier, Grenoble, France (in French).

Custódio, S., P. Liu, and R. J. Archuleta (2005). The $2004 M_{\mathrm{w}} 6.0$ Parkfield, California, earthquake: Inversion of near-source ground motion using multiple data sets, Geophys. Res. Lett. 32, L23312, doi: 10.1029/2005GL024417.

Day, S. M., G. Yu, and D. J. Wald (1998). Dynamic stress changes during earthquake rupture, Bull. Seismol. Soc. Am. 88, 512-522

Delouis, B., D. Giardini, P. Lundgren, and J. Salichon (2002). Joint inversion of InSAR, GPS, teleseismic, and strong-motion data for the spatial and temporal distribution of earthquake slip: Application to the 1999 Izmit mainshock, Bull. Seismol. Soc. Am. 92, 278-299.

Dettmer, J., R. Benavente, P. R. Cummins, and M. Sambridge (2014). Transdimensional finite-fault inversion, Geophys. J. Int. 199, 735-751.

Dreger, D. S. (1994). Empirical Green's function study of the January 17, 1994 Northridge, California earthquake, Geophys. Res. Lett. 21, 2633-2636.

Dunham, E. M., and R. J. Archuleta (2004). Evidence for a supershear transient during the 2002 Denali fault earthquake, Bull. Seismol. Soc. Am. 94, S256-S268, doi: 10.1785/0120040616.

Duputel, Z., L. Rivera, Y. Fukahata, and H. Kanamori (2012). Uncertainty estimations for seismic source inversions, Geophys. J. Int. 190, doi: 10.1111/j.1365-246X.2012.05554.x.

Eddy, D.M., W. Hollingworth, J. J. Caro, J. Tsevat, K. M. McDonald, and J. B. Wong (2012). Model transparency and validation: A report of the ISPOR-SMDM Modeling Good Research Practices Task Force7, Med. Decis. Making 32, 733-743.

Ely, G. P., S. M. Day, and J. B. Minster (2008). A support-operator method for viscoelastic wave modelling in 3-D heterogeneous media, Geophys. J. Int. 172, no. 1, 331-344.

Fan, W., and P. M. Shearer (2015). Detailed rupture imaging of the 25 April 2015 Nepal earthquake using teleseismic $P$ waves, Geophys. Res. Lett. 42, doi: 10.1002/2015GL064587.

Fan, W., P. M. Shearer, and P. Gerstoft (2014). Kinematic earthquake rupture inversion in the frequency domain, Geophys. J. Int. 199, $1138-1160$
Friederich, W., and J. Dalkolmo (1995). Complete synthetic seismograms for a spherical symmetric Earth by a numerical computation of the Green's function in the frequency domain, Geophys. J. Int. 122, 537-550.

Gabriel, A. A., J.-P. Ampuero, L. A. Dalguer, and P. M. Mai (2012). The transition of dynamic rupture modes in elastic media, J. Geophys. Res. 117, no. B9, doi: 10.1029/2012JB009468.

Gallovic, F., and J.-P. Ampuero (2015). A new strategy to compare inverted rupture models exploiting the eigen-structure of the inverse problem, Seismol. Res. Lett. 86, 1679-1689.

Gallovic, F., W. Imperatori, and P. M. Mai (2015). Effects of three-dimensional crustal structure and smoothing constraint on earthquake slip inversions: Case study of the $M_{\mathrm{w}} 6.32009$ L'Aquila earthquake, J. Geophys. Res. 120, 428-449, doi: 10.1002/2014JB011650.

Graves, R. W., and D. J. Wald (2001). Resolution analysis of finite fault source inversion using one- and three-dimensional Green's functions 1. Strong motions, J. Geophys. Res. 106, 8745-8766.

Gusev, A. A. (2011). Statistics of the values of a normalized slip in the points of an earthquake fault, Izvestiya Phys. Solid Earth 47, $176-185$.

Harris, R. A., M. Barall, R. Archuleta, B. Aagaard, J.-P. Ampuero, H. Bhat, V. Cruz-Atienza, L. Dalguer, P. Dawson, S. Day, et al. (2009). The SCEC/USGS Dynamic Earthquake Rupture Code Verification Exercise, Seismol. Res. Lett. 80, 119-126.

Hartzell, S. H., and T. H. Heaton (1983). Inversion of strong ground motion and teleseismic waveform data for the fault rupture history of the 1979 Imperial Valley, California, earthquake, Bull. Seismol. Soc. Am. 73, 1553-1583.

Hartzell, S., P. Liu, and C. Mendoza (1996). The 1994 Northridge, California, earthquake: Investigation of rupture velocity, risetime, and high-frequency radiation, J. Geophys. Res. 101, 20,091-20,108.

Hartzell, S., P. Liu, C. Mendoza, C. Ji, and K. M. Larson (2007). Stability and uncertainty of finite-fault slip inversions: Application to the 2004 Parkfield, California, earthquake, Bull. Seismol. Soc. Am. 97, 1911-1934.

Hayes, G. (2011). Rapid source characterization of the $2011 M_{\mathrm{w}} 9.0$ Off the Pacific Coast of Tohoku earthquake, Earth Planets Space 63, 529-534.

Heaton, T. H. (1990). Evidence for and implications of self-healing pulses of slip in earthquake rupture, Phys. Earth Planet. In. 64, 1-20.

Hering, A., and M. G. Genton (2011). Comparing spatial predictions, Technometrics 53, 414-425.

Ide, S. (2007). Slip inversion, in Treatise on Geophysics, in Earthquake Seismology, H. Kanamori (Series Editor), Vol. 4, Elsevier, Amsterdam, The Netherlands, 193-224, ISBN: 978-0-444-51932-0.

Ide, S., and M. Takeo (1997). Determination of constitutive relations of fault slip based on seismic waves analysis, J. Geophys. Res. 102, 27,379-27,391.

Ide, S., G. C. Beroza, and J. J. Mcguire (2005). Imaging earthquake source complexity, in Seismic Earth: Array Analysis of Broadband Seismograms, A. Levander and G. Nolet (Editors), American Geophysical Union, Washington, D.C., doi: 10.1029/157GM08.

Imperatori, W., and P. M. Mai (2012). Sensitivity of broad-band groundmotion simulations to earthquake source and Earth structure variations: An application to the Messina Straits (Italy), Geophys. J. Int. 118, 1103-1116, doi: 10.1111/j.1365-246X.2011.05296.x.

Imperatori, W., and P. M. Mai (2013). Broadband near-field ground-motion simulations in 3D scattering media, Geophys. J. Int. 192, 725-744.

Ishii, M., P. M. Shearer, H. Houston, and J. E. Vidale (2005). Extent, duration and speed of the 2004 Sumatra-Andaman earthquake imaged by the Hi-net array, Nature 435, 933-936.

Jónsson, S., H. Zebker, P. Segall, and F. Amelung (2002). Fault slip distribution of the $1999 M_{\mathrm{w}} 7.1$ Hector Mine, California, earthquake, estimated from satellite radar and GPS measurements, Bull. Seismol. Soc. Am. 92, 1377-1389.

Käser, M., and M. Dumbser (2006). An arbitrary high order discontinuous Galerkin method for elastic waves on unstructured meshes, I: 
The two-dimensional isotropic case with external source terms, Geophys. J. Int. 166, 855-877.

Käser, M., P. M. Mai, and M. Dumbser (2007). Accurate calculation of fault rupture models using the high-order discontinuous Galerkin method on tetrahedral meshes, Bull. Seismol. Soc. Am. 97, 15701586.

Kikuchi, M., and H. Kanamori (1991). Inversion of complex body waves III, Bull. Seismol. Soc. Am. 81, 2335-2350.

King, G. C. P., R. S. Stein, and J. Lin (1994). Static stress changes and the triggering of earthquakes, Bull. Seismol. Soc. Am. 84, 935-953.

Kiser, E., and M. Ishii (2012). Combining seismic arrays to image the highfrequency characteristics of large earthquakes, Geophys. J. Int. 188, 1117-1128, doi: 10.1111/j.1365-246X.2011.05299.x.

Kohler, M. D., H. Magistrale, and R. W. Clayton (2003). Mantle heterogeneities and the SCEC reference three-dimensional seismic velocity model version 3, Bull. Seismol. Soc. Am. 93, 757-774.

Konca, A. O., Y. Kaneko, N. Lapusta, and J. P. Avouac (2013). Kinematic inversion of physically plausible earthquake source models obtained from dynamic rupture simulations, Bull. Seismol. Soc. Am. 103, 2621-2644.

Koper, K. D., A. H. T. Lay, C. Ammon, and H. Kanamori (2011). Frequency-dependent rupture process of the $2011 M_{\mathrm{w}} 9.0$ Tohoku earthquake: Comparison of short-period P-wave backprojection images and broadband seismic rupture models, Earth Planets Space 63, 599-602.

Kristekova, M., J. Kristek, and P. Moczo (2009). Time-frequency misfit and goodness-of-fit criteria, Geophys. J. Int. 178, 813-825, doi: 10.1111/j.1365-246X.2009.04177.x.

Krüger, F., and M. Ohrnberger (2005). Tracking the rupture of the $M_{\mathrm{w}}=9.3$ Sumatra earthquake over $1150 \mathrm{~km}$ at teleseismic distance, Nature 435, no. 7044, 937-939, doi: 10.1038/nature03696.

Lavallée, D., P. Liu, and R. J. Archuleta (2006). Stochastic model of heterogeneity in earthquake slip spatial distributions, Geophys. J. Int. 165, 622-640.

Lee, S.-J., B.-S. Huang, M. Ando, H.-C. Chiu, and J.-H. Wang (2011). Evidence of large scale repeating slip during the 2011 Tohoku-Oki earthquake, Geophys. Res. Lett. 38, L19306, doi: 10.1029/ 2011GL049580.

Lees, J. M. (2012). Open and free: Software and scientific reproducibility, Seismol. Res. Lett. 83, 751-752, doi: 10.1785/0220120091.

Liu, P., and R. J. Archuleta (2004). A new nonlinear finite fault inversion with three-dimensional Green's functions: Application to the 1989 Loma Prieta, California, earthquake, J. Geophys. Res. 109, no. B02318, doi: 10.1029/2003JB002625.

Liu, P., S. Custódio, and R. J. Archuleta (2006). Kinematic inversion of the $2004 M_{\mathrm{w}} 6.0$ Parkfield earthquake including an approximation to site effects, Bull. Seismol. Soc. Am. 96, S143-S158, doi: 10.1785/ 0120050826.

Mai, P. M. (2009) Ground motion: Complexity and scaling in the near field of earthquake ruptures, in Encyclopedia of Complexity and Systems Science, W. H. K. Lee and R. Meyers (Editors), Springer, New York, 4435-4474, ISBN 978-0-387-30440-3.

Mai, P. M., and G. C. Beroza (2000). Source-scaling properties from finite-fault rupture models, Bull. Seismol. Soc. Am. 90, 604-615.

Mai, P. M., and G. C. Beroza (2002). A spatial random-field model to characterize complexity in earthquake slip, J. Geophys. Res. 107, doi: 10.1029/2001JB000588.

Mai, P. M., and K. K. S. Thingbaijam (2014). SRCMOD: An online database of finite source rupture models, Seismol. Res. Lett. 85, 1348-1357.

Mai, P.M., J. Burjanek, B. Delouis, G. Festa, C. Francois-Holden, D. Monelli, T. Uchide, and J. Zahradnik (2007). Earthquake source inversion blindtest: Initial results and further developments, Eos Trans. $A G U$ 88, no. 52, Fall Meet. Suppl., Abstract S53C-08.

Mai, P. M., P. Shearer, J.-P. Ampuero, and Th. Lay (2016). Standards for documenting finite-fault earthquake rupture models, Seismol. Res. Lett. 87, no. 3, doi: 10.1785/0220150204.
Mai, P. M., P. Somerville, A. Pitarka, L. Dalguer, H. Miyake, G. Beroza, S.-G. Song, and K. Irikura (2006). Fracture-energy scaling in dynamic rupture models of past earthquakes, in Earthquakes: Radiated Energy and the Physics of Faulting, A. McGarr, R. Abercrombie, and H. Kanamori (Editors), Geophysical Monograph Series, Vol. 170, 283-294

Mai, P. M, P. Spudich, and J. Boatwright (2005). Hypocenter locations in finite-source rupture models, Bull. Seismol. Soc. Am. 95, 965-980.

Manighetti, I., M. Campillo, C. Sammis, P.M. Mai, and G. King (2005). Evidence for self-similar, triangular slip distributions on earthquakes: Implications for earthquake and fault mechanics, J. Geophys. Res. 110, no. B05302, doi: 10.1029/2004JB003174.

Meng, L., J.-P. Ampuero, J. Stock, Z. Duputel, Y. Luo, and V. C. Tsai (2012). Earthquake in a maze: Compressional rupture branching during the $2012 M_{\mathrm{w}} 8.6$ Sumatra earthquake, Science 337, 724726, doi: $10.1126 /$ science. 1224030 .

Meng, L., A. Inbal, and J.-P. Ampuero (2011). A window into the complexity of the dynamic rupture of the $2011 M_{\mathrm{w}} 9$ Tohoku-Oki earthquake, Geophys. Res. Lett. 38, doi: 10.1029/2011GL048118.

Mesirov, J. P. (2010). Accessible reproducible research, Science 327, 415416, doi: $10.1126 /$ science.1179653.

Minson, S. E., M. Simons, and J. L. Beck (2013). Bayesian inversion for finite fault earthquake source models I-Theory and algorithm, Geophys. J. Int. 194, 1701-1726.

Monelli, D., and P. M. Mai (2008). Bayesian inference of kinematic earthquake rupture parameters through fitting of strong motion data, Geophys. J. Int. 173, 220-232, doi: 10.1111/j.1365-246X. 2008.03733.x.

Monelli, D., P. M. Mai, S. Jónsson, and D. Giardini (2009). Bayesian imaging of the 2000 Western Tottori (Japan) earthquake through fitting of strong motion and GPS data, Geophys. J. Int. 176, 135150, doi: 10.1111/j.1365-246X.2008.03943.x.

Nissen-Meyer, T., M. van Driel, S. C. Stähler, K. Hosseini, S. Hempel, L. Auer, A. Colombi, and A. Fournier (2014). AxiSEM: Broadband 3D seismic wavefields in axisymmetric media, Solid Earth 5, 425445, doi: 10.5194/se-5-425-2014.

Olson, A. H., and R. J. Apsel (1982). Finite faults and inverse theory with applications to the 1979 Imperial Valley earthquake, Bull. Seismol. Soc. Am. 72, 1969-2001.

Olson, A. H., J. A. Orcutt, and G. A. Frazier (1984). The discrete wavenumber/finite element method for synthetic seismograms, Geophys. J. Roy. Astron. Soc. 77, 421-460.

Page, M. T., E. M. Dunham, and J. Carlson (2005). Distinguishing barriers and asperities in near-source ground motion, J. Geophys. Res. no. B11302, doi: 10.1029/2005JB003736.

Page, M., P. M. Mai, and D. Schorlemmer (2011). Testing earthquake source inversion methodologies, Eos Trans. $A G U$ 92, no. 9, 75.

Razafindrakoto, H. N. T., and P. M. Mai (2014). Uncertainty in earthquake source imaging due to variations in source time function and Earth structure, Bull. Seismol. Soc. Am. 104, 855-874, doi: $10.1785 / 0120130195$.

Razafindrakoto, H. N. T, P. M. Mai, M. G. Genton, L. Zhang, and K. K. S. Thingbaijam (2015). Quantifying variability in earthquake rupture models using multidimensional scaling: Application to the 2011 Tohoku earthquake, Geophys. J. Int. 202, 17-40, doi: $10.1093 / \mathrm{gji} / \mathrm{ggv} 088$.

Satake, K., Y. Fujii, T. Harada, and Y. Namegaya (2013). Time and space distribution of coseismic slip of the 2011 Tohoku earthquake as inferred from tsunami waveform data, Bull. Seismol. Soc. Am. 103, 1473-1492.

Sekiguchi, H., and T. Iwata (2002). Rupture process of the 1999 Kocaeli, Turkey, earthquake estimated from strong-motion waveforms, Bull. Seismol. Soc. Am. 92, 300-311.

Somerville, P., K. Irikura, R. Graves, S. Sawada, D. Wald, N. Abrahamson, Y. Iwasaki, T. Kagawa, N. Smith, and A. Kowada (1999) Characterizing crustal earthquake slip models for the prediction of strong ground motion, Seismol. Res. Lett. 70, 59-80. 
Spudich, P., and L. Xu (2002). Documentation of Software Package Compsyn sxv3.11: Programs for Earthquake Ground Motion Calculation Using Complete 1-D Green's Functions, International Handbook of Earthquake and Engineering Seismology, Academic Press, London.

Stein, R. S., A. A. Barka, and J. H. Dieterich (1997). Progressive failure on the North Anatolian fault since 1939 by earthquake stress triggering, Geophys. J. Int. 128, 594-604.

Strasser, F. O., M. C. Arango, and J. J. Bommer (2010). Scaling of the source dimensions of interface and intraslab subduction-zone earthquakes with moment magnitude, Seismol. Res. Lett. 81, 941-950.

Tinti, E., P. Spudich, and M. Cocco (2005). Earthquake fracture energies inferred from kinematic rupture models on extended faults, J. Geophys. Res. 110, no. B12303, doi: 10.1029/2005JB003644.

van Driel, M., L. Krischer, S. C. Stähler, K. Hosseini, and T. NissenMeyer (2015). Instaseis: Instant global seismograms based on a broadband waveform database, Solid Earth 6, 701-717, doi: $10.5194 / \mathrm{se}-6-701-2015$.

Wald, D. J., and R. W. Graves (2001). Resolution analysis of finite fault source inversion using one-and three-dimensional Green's functions: 2. Combining seismic and geodetic data, J. Geophys. Res. 106, 8767-8788.

Wald, D. J., D. V. Helmberger, and T. H. Heaton (1991). Rupture model of the 1989 Loma Prieta earthquake from the inversion of strongmotion and broadband teleseismic data, Bull. Seismol. Soc. Am. 81, $1540-1572$.

Yagi, Y., and M. Kikuchi (2000). Source rupture process of the Kocaeli, Turkey, earthquake of August 17, 1999, obtained by joint inversion of near-field data and teleseismic data, Geophys. Res. Lett. 27, 19691972.

Yoshida, S., K. Koketsu, B. Shibazaki, T. Sagiya, T. Kato, and Y. Yoshida (1996). Joint inversion of near- and far-field waveform and geodetic data for the rupture process of the 1995 Kobe earthquake, J. Phys. Earth 44, no. 5, 437-454.

Yue, H, T. Lay, and K. D. Koper (2012). En echelon and orthogonal fault ruptures of the 11 April 2012 Great Intraplate earthquakes, Nature 490, 245-249, doi: 10.1038/nature11492.

Zechar, J. D., D. Schorlemmer, M. Liukis, J. Yu, F. Euchner, P. J. Maechling, and T. H. Jordan (2010). The Collaboratory for the Study of Earthquake Predictability perspective on computational earthquake science, Concurrency Comput. Pract. Ex. 22, $1836-1847$.

Zhang, L., P. M. Mai, K. K. S. Thingbaijam, H. N. Razafindrakoto, and M. Genton (2015). Comparing earthquake slip models with the spatial prediction comparison test, Geophys. J. Int. 200, 185-198, doi: $10.1093 / \mathrm{gji} / \mathrm{ggu} 383$.

Zhang, Y., R. Wang, J. Zschau, Y. T. Chen, S. Parolai, and T. Dahm (2014). Automatic imaging of earthquake rupture processes by iterative deconvolution and stacking of high-rate GPS and strong motion seismograms, J. Geophys. Res. 119, 5633-5650.

Zhu, L., and L. A. Rivera (2002). A note on the dynamic and static displacements from a point source in multilayered media, Geophys. J. Int. 148, 619-627.

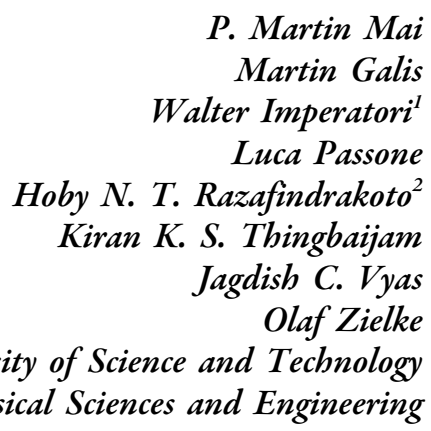

Thuwal 23955-6900, Kingdom of Saudi Arabia martin.mai@kaust.edu.sa

Danijel Schorlemmer Rongjiang Wang Geo-Forschungszentrum Potsdam, GFZ Telegrafenberg 14473 Potsdam, Germany

Morgan Page

U.S. Geological Survey 525 South Wilson Avenue Pasadena, California 91106 U.S.A.

Jean-Paul Ampuero California Institute of Technology Seismological Laboratory

1200 East California Boulevard

MC 252-21 Pasadena, California 91125 U.S.A.

Kimiyuki Asano Haruko Sekiguchi Disaster Prevention Research Institute Kyoto University Gokasho, Uji Kyoto 611-0011, Japan

Mathieu Causse ISTerre

Universite Grenoble Alpes, IFSTTAR, CNRS CS 40700 38058 Grenoble Cedex 9, France

Susana Custodio Instituto Dom Luiz Faculdade de Ciencias Universidade de Lisboa 1749-016 Lisboa, Portugal

Wenyuan Fan University of California, San Diego Scripps Institution of Oceanography IGPP 0225 La Jolla, California 92093-0225 U.S.A.

Gaetano Festa
Department of Physics
Università di Napoli Federico II
Naples, Italy
Frantisek Gallovic
Charles University in Prague
Faculty of Mathematics and Physics
Department of Geophysics




\section{Holešovičkách 2 18000 Praba 8 Czech Republic}

Martin Käser

Department of Earth and Environmental Sciences Ludwig-Maximilian University Theresienstr. 41 80333 Munich, Germany

Dmytro Malytskyy Carpathian Branch of Subbotin Institute of Geophysics National Academy of Sciences of Ukraine Lviv 79060 Ukraine

Ryo Okuwaki

Yuji Yagi

Faculty of Life and Environmental Sciences University of Tsukuba 1-1-1 Tennodai, Tsukuba Ibaraki 305-8572, Japan

Fred Pollitz Earthquake Science Center U.S. Geological Survey 345 Middlefield Rd., MS 977 Menlo Park, California 94025 U.S.A.

Seok Goo Song Earthquake Research Center
Korea Institute of Geoscience and Mineral Resources (KI-

124 Gwabang-no, Yuseong-gu Daejeon 34132, South Korea

Surendra N. Somala Department of Civil Engineering Indian Institute of Technology (IIT) Hyderabad Hyderabad, India 502285

Cedric Twardzik

Department of Earth Science 1006 Webb Hall

University of California, Santa Barbara Santa Barbara, California 93106-9630 U.S.A.

Martin van Driel Department of Earth Sciences, ETH Zürich Sonneggstrasse 5 8092 Zurich, Switzerland

Published Online 6 April 2016

${ }^{1}$ Also at Department of Earth Sciences, ETH Zürich, Sonneggstrasse 5, 8092 Zurich, Switzerland.

${ }^{2}$ Also at Department of Civil and Natural Resources Engineering, University of Canterbury, Christchurch 8040, New Zealand. 